\title{
High spatial resolution imaging of methane and other trace gases with the airborne Hyperspectral Thermal Emission Spectrometer (HyTES)
}

\author{
Glynn C. Hulley ${ }^{1}$, Riley M. Duren ${ }^{1}$, Francesca M. Hopkins ${ }^{1}$, Simon J. Hook ${ }^{1}$, Nick Vance ${ }^{1}$, Pierre Guillevic ${ }^{2}$, \\ William R. Johnson ${ }^{1}$, Bjorn T. Eng ${ }^{1}$, Jonathan M. Mihaly ${ }^{1}$, Veljko M. Jovanovic ${ }^{1}$, Seth L. Chazanoff ${ }^{1}$, \\ Zak K. Staniszewski ${ }^{1}$, Le Kuai ${ }^{1}$, John Worden ${ }^{1}$, Christian Frankenberg ${ }^{4}$, Gerardo Rivera ${ }^{1}$, Andrew D. Aubrey ${ }^{1}$, \\ Charles E. Miller ${ }^{1}$, Nabin K. Malakar ${ }^{1}$, Juan M. Sánchez Tomás ${ }^{3}$, and Kendall T. Holmes ${ }^{1}$ \\ ${ }^{1}$ Jet Propulsion Laboratory, California Institute of Technology, Pasadena, CA 91109, USA \\ ${ }^{2}$ Department of Geographical Sciences, University of Maryland, College Park, MD 20742, USA \\ ${ }^{3}$ Universidad de Castilla-La Mancha, Ciudad Real, Spain \\ ${ }^{4}$ California Institute of Technology, Pasadena, CA 91109, USA
}

Correspondence to: Glynn C. Hulley (glynn.hulley@jpl.nasa.gov)

Received: 11 January 2016 - Published in Atmos. Meas. Tech. Discuss.: 25 February 2016

Revised: 9 May 2016 - Accepted: 16 May 2016 - Published: 1 June 2016

\begin{abstract}
Currently large uncertainties exist associated with the attribution and quantification of fugitive emissions of criteria pollutants and greenhouse gases such as methane across large regions and key economic sectors. In this study, data from the airborne Hyperspectral Thermal Emission Spectrometer (HyTES) have been used to develop robust and reliable techniques for the detection and wide-area mapping of emission plumes of methane and other atmospheric trace gas species over challenging and diverse environmental conditions with high spatial resolution that permits direct attribution to sources. HyTES is a pushbroom imaging spectrometer with high spectral resolution ( 256 bands from 7.5 to $12 \mu \mathrm{m}$ ), wide swath $(1-2 \mathrm{~km})$, and high spatial resolution $(\sim 2 \mathrm{~m}$ at $1 \mathrm{~km}$ altitude) that incorporates new thermal infrared (TIR) remote sensing technologies. In this study we introduce a hybrid clutter matched filter (CMF) and plume dilation algorithm applied to HyTES observations to efficiently detect and characterize the spatial structures of individual plumes of $\mathrm{CH}_{4}, \mathrm{H}_{2} \mathrm{~S}, \mathrm{NH}_{3}, \mathrm{NO}_{2}$, and $\mathrm{SO}_{2}$ emitters. The sensitivity and field of regard of HyTES allows rapid and frequent airborne surveys of large areas including facilities not readily accessible from the surface. The HyTES CMF algorithm produces plume intensity images of methane and other gases from strong emission sources. The combination of high spatial resolution and multi-species imaging capability provides
\end{abstract}

source attribution in complex environments. The CMF-based detection of strong emission sources over large areas is a fast and powerful tool needed to focus on more computationally intensive retrieval algorithms to quantify emissions with error estimates, and is useful for expediting mitigation efforts and addressing critical science questions.

\section{Introduction}

The Hyperspectral Thermal Emission Spectrometer (HyTES) is a pushbroom imaging spectrometer that produces a wide-swath thermal infrared (TIR) image with high spectral (256 bands from 7.5 to $12 \mu \mathrm{m}$ ) and spatial resolution ( $\sim 2 \mathrm{~m}$ at $1 \mathrm{~km}$ altitude) (Hook et al., 2013, 2016). HyTES incorporates a number of technologies, which presents a major advance in airborne TIR hyperspectral remote sensing measurements (Johnson et al., 2009, 2012). While hyperspectral imaging spectrometers operating in the visible to short-wave infrared spectrum (VSWIR, 1400 $2500 \mathrm{~nm}$ ), such as the Next Generation Airborne Visible Infrared Imaging Spectrometer (AVIRIS-NG) (Green et al., 1998), rely on reflected solar radiance to detect various chemical gas species such as methane $\left(\mathrm{CH}_{4}\right)$ (Roberts et al., 2010; Thompson et al., 2015; Thorpe et al., 2013, 2014), 
TIR spectrometers instead rely on the thermal emission and thermal contrast between ground and target gas alone. This has the advantage of making detection more robust over a wider range of land cover types independent of their reflective features. For example, given sufficient thermal contrast between the plume and the surface, TIR data should on average have higher sensitivity to methane detection than SWIR data over low albedo surfaces such as seawater and dark vegetation, and particularly at higher latitudes where reduced reflective solar insolation makes it a challenge for current SWIR instrument capabilities. This is because thermal contrast can change rapidly with local atmospheric conditions over much shorter timescales than the underlying reflective surface features such as water and dark vegetation of which the SWIR instruments are responsive to. These kinds of conditions would be typical of the Arctic region, for example, which contains large reservoirs in the form of methane hydrates at the ocean surface and in permafrost regions (Damm et al., 2010; Kort et al., 2012). TIR observations also allow nighttime operation during which the collapsed nocturnal planetary boundary layer results in higher near-surface concentrations of source gases translating to easier detection. Another key advantage of TIR hyperspectral data is the ability to distinguish between both greenhouse gases (e.g., $\mathrm{CH}_{4}$ ) and criteria pollutants such as hydrogen sulfide $\left(\mathrm{H}_{2} \mathrm{~S}\right)$, ammonia $\left(\mathrm{NH}_{3}\right)$, nitrogen dioxide $\left(\mathrm{NO}_{2}\right)$, and sulfur dioxide $\left(\mathrm{SO}_{2}\right)$ within a single plume - a capability that will be demonstrated in this work.

TIR remote sensing has a long heritage of medium to high spatial resolution airborne and spaceborne sensors with multiple (3-10) bands in the TIR region, starting with the sixband Thermal Infrared Multispectral Scanner (TIMS) airborne sensor in the early 1980s (Kahle and Goetz, 1983) and followed by the MODIS/ASTER (MASTER) airborne sensor with 10 bands in the TIR region (Hook et al., 2001). However, one of the biggest drawbacks of these imagers is their limited number of spectral bands defining the TIR region $(7.5-12 \mu \mathrm{m})$. In response, a number of hyperspectral TIR sensors have been developed, starting with the narrow field-of-view SEBASS (Spatially Enhanced Broadband Array Spectograph System) (Hackwell et al., 1996), and including wide-swath capabilities such as MAKO (Warren et al., 2010), the Mineral and Gas Identifier (MAGI) (Hall et al., 2008, 2015), AisaOWL (Doneus et al., 2014), SIELETERS (Ferrec et al., 2014), and HyTES (Hook et al., 2013). Table 1 compares the instrument characteristics of each of these six sensors. Of these instruments, HyTES has the highest number of spectral bands (256), which will improve the detection sensitivity of trace gas species, particularly those gases with sharp spectral features. For example, using a set of $\sim 50$ gases a study by Hall et al. (2008) found that species with sharp spectral features such as $\mathrm{H}_{2} \mathrm{~S}$ and $\mathrm{NH}_{3}$ suffered the greatest sensitivity loss from reduced spectral resolution when simulating the relative sensitivity of data with 64,32 , and 16 spectral channels. HyTES has sufficient spectral in- formation in the 7.5-12 $\mu \mathrm{m}$ region to resolve the spectral absorption signatures of a variety of different trace gases including $\mathrm{CH}_{4}, \mathrm{NH}_{3}, \mathrm{H}_{2} \mathrm{~S}, \mathrm{SO}_{2}$ and $\mathrm{NO}_{2}$.

Airborne hyperspectral imagers such as HyTES have a wide-swath mapping capability and fine spatial resolution, making them very useful for the detection of discrete sources of gaseous emissions over large regions, which is otherwise difficult from ground or airborne lidar measurements alone (Thorpe et al., 2014; Tratt et al., 2014). In the context of climate change and air quality, the ability to detect and characterize individual point sources of greenhouse gases such as methane or criteria pollutants such as sulfur and nitrogen oxides from key emitting sectors is a promising tool for improving understanding of the distribution of emissions sources and for supporting emissions mitigation.

In this work we present the theory and methodologies for the rapid detection of a variety of trace gas species $\left(\mathrm{CH}_{4}\right.$, $\mathrm{NO}_{2}, \mathrm{NH}_{3}, \mathrm{H}_{2} \mathrm{~S}$, and $\mathrm{SO}_{2}$ ) from the HyTES hyperspectral TIR data, with a focus on methane. We introduce a hybrid clutter matched filter (CMF) and plume dilation algorithm for efficiently detecting and imaging trace gas plumes. We present representative results from field testing including the detection of anthropogenic $\mathrm{CH}_{4}$ sources over challenging areas such as urban Los Angeles, where thermal in-scene clutter makes detection difficult, and over managed systems such as dairy farms, and oil fields in the San Joaquin Valley (SJV), California. The sites were chosen to test the HyTES gas detection technique in a variety of different settings related to a range of science applications, and to provide in situ measurements to validate those results. For example, contemporaneous surface $\mathrm{CH}_{4}$ measurements were made from vehicles with on-board Picarro G2401 or G1301 analyzers while driving along public roads in the domain of HyTES overflights during campaigns over the La Brea tar pits in Los Angeles during 2014, and during February 2015 in the Kern River oil field. The primary science goal of the HyTES flights over these sites was to detect, attribute, and characterize the spatial structure of $\mathrm{CH}_{4}$ plumes to better understand their distribution and enable follow up measurements, and identify high-priority sources for follow-up analysis with more computationally intensive quantitative retrievals (Kuai et al., 2016). We also demonstrate the ability of the technique to image different chemical species such as $\mathrm{NH}_{3}, \mathrm{H}_{2} \mathrm{~S}, \mathrm{SO}_{2}$, and $\mathrm{NO}_{2}$ within the same plume. HyTES Level-1 radiance data and Level-2 Surface Temperature and Emissivity data from the 2013, 2014, and 2015 campaigns are free and available for ordering at http://hytes.jpl.nasa.gov/order (Jet Propulsion Laboratory, 2016).

\section{HyTES background}

\subsection{Instrument}

The HyTES instrument is a Dyson optical configuration with a compact hyperspectral grating spectrometer acquir- 
Table 1. Instrument characteristics of well demonstrated airborne hyperspectral long-wave thermal infrared systems.

\begin{tabular}{|c|c|c|c|c|c|c|c|c|c|}
\hline Instrument & $\begin{array}{c}\text { First } \\
\text { deployed }\end{array}$ & Bands & $\begin{array}{l}\text { Spectral } \\
\text { range } \\
(\mu \mathrm{m})\end{array}$ & $\begin{array}{r}\text { Spectral } \\
\text { resolution } \\
(\mathrm{nm})\end{array}$ & $\begin{array}{l}\text { IFOV }^{\mathrm{c}} \\
(\mathrm{mrad})\end{array}$ & $\begin{array}{l}\text { Max } \\
\text { scan } \\
\left({ }^{\circ}\right)\end{array}$ & $\begin{array}{r}\text { Pixels } \\
\text { X-track }\end{array}$ & $\begin{array}{l}\text { NEDT }^{\mathrm{a}} \\
(\mathrm{K})\end{array}$ & Detector \\
\hline AISA-OWL ${ }^{\mathrm{d}}$ & 2014 & 96 & $7.7-12.3$ & 100 & 1.10 & \pm 24 & 384 & $25^{b}$ & $\mathrm{HgCdTe}$ \\
\hline HyTES & 2013 & 256 & $7.5-12$ & 18 & 1.70 & \pm 25 & 512 & 0.20 & QWIP \\
\hline MAGI $^{f}$ & 2011 & 32 & $7.1-12.7$ & 175 & 0.53 & \pm 42 & 2800 & 0.10 & $\mathrm{HgCdTe}$ \\
\hline Sieleters B3 ${ }^{\mathrm{g}}$ & 2011 & 38 & $8-11.5$ & 80 & 0.25 & \pm 7 & - & 0.15 & $\mathrm{HgCdTe}$ \\
\hline MAKO $^{\mathrm{h}}$ & 2010 & 128 & $7.45-13.5$ & 47 & 0.55 & \pm 45 & $400-2750$ & 0.05 & $\mathrm{Si}: \mathrm{As}$ \\
\hline SEBASS $^{i}$ & 1995 & 128 & $7.6-13.5$ & 46 & 1.10 & \pm 3.6 & 128 & 0.05 & $\mathrm{Si}: \mathrm{As}$ \\
\hline LWHIS $^{j}$ & 2003 & 128 & $8-12.5$ & 35 & 0.9 & \pm 3.25 & 128 & 0.035 & $\mathrm{HgCdTe}$ \\
\hline
\end{tabular}

${ }^{a}$ NEDT is the noise equivalent differential temperature (K); ${ }^{b}$ NESR is the noise equivalent spectral radiance $\left(\mathrm{mW} \mathrm{m}^{-2} \mathrm{sr}^{-1} \mu \mathrm{m}^{-1}\right) ;{ }^{\mathrm{c}}$ IFOV is the instantaneous field of view; ${ }^{\mathrm{d}}$ Specim (Finland); ${ }^{\mathrm{e}}$ Jet Propulsion Laboratory (USA); $\mathrm{f}, \mathrm{h}, \mathrm{i}$ The Aerospace Corporation (USA); ${ }^{\mathrm{g}}$ Onera (France); ${ }^{\mathrm{j}}$ Northrop Grumman Space Technology (USA).

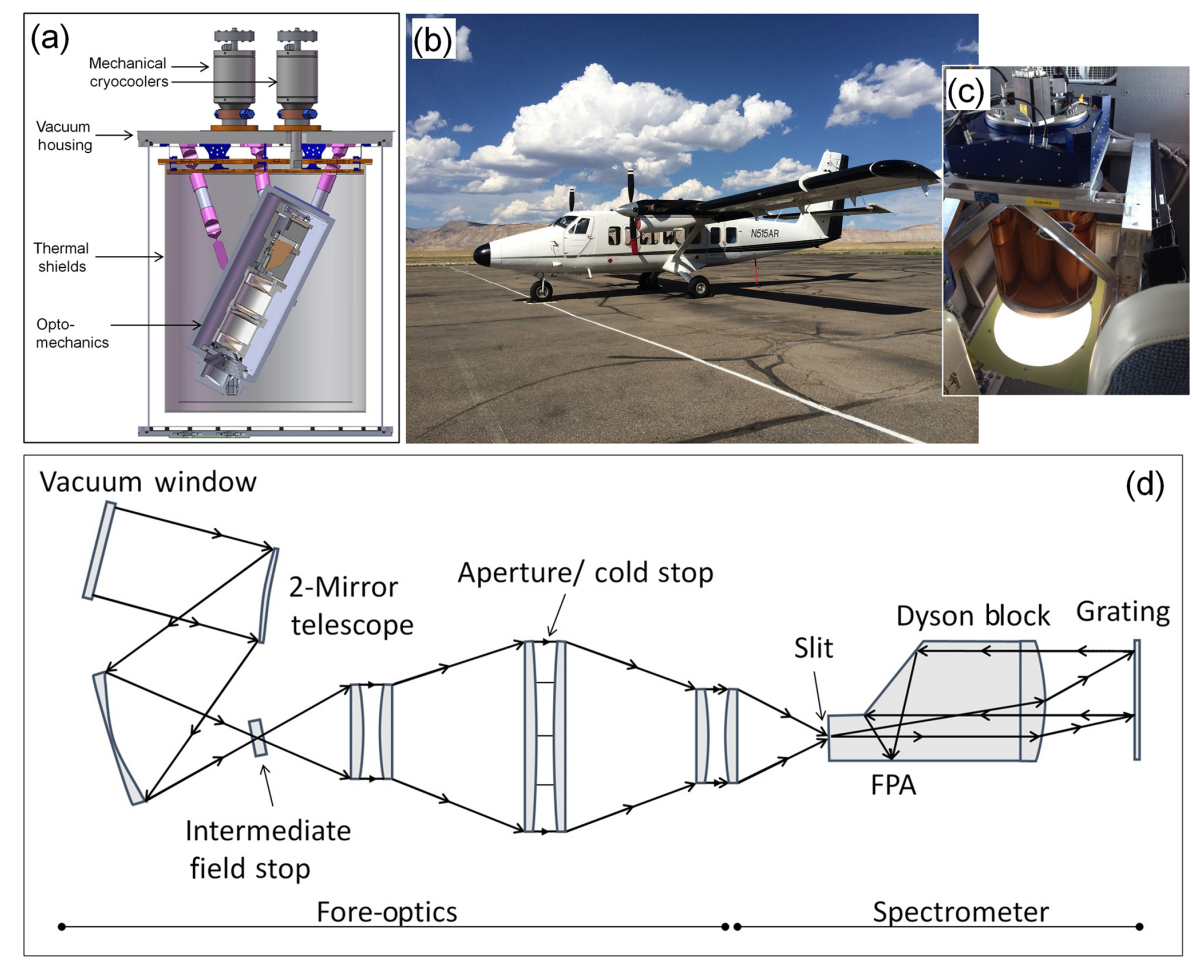

Figure 1. (a) HyTES design and optical layout, (b) Twin Otter aircraft, (c) HyTES installation in aircraft, and (d), optical layout highlighting ray trace through the Dyson spectrometer and objective lens elements.

ing data in 256 spectral bands in the TIR range from 7.5 to $12 \mu \mathrm{m}$ (Fig. 1), and a Quantum Well Infrared Photodetector (QWIP) (Gunapala et al., 2006). This is the first integration of the QWIP with a spectrometer imaging system for Earth science studies that require well-calibrated data. A major advantage of the instrument is its very compact design due to its small form factor and low power requirement $(1 \mathrm{~kW})$ when compared to what the aircraft can support $(4 \mathrm{~kW})$ (Johnson et al., 2012). A vacuum chamber is used to keep the focal plane system cold using two mechanical cryocoolers (Fig. 1). The chamber has also been proven to support airborne operation of other VSWIR instruments, while maintaining rigidity of its inner precision and optical components. A full description of the HyTES instrument including instrument performance, calibration, and validation is provided by Hook et al. (2016).

HyTES is currently configured to fly on the Twin Otter aircraft and Fig. 1 shows the aircraft and the HyTES instrument looking nadir in flight. For Twin Otter flights, the instrument is calibrated before and after each flight (including any intermediate stops), and the nominal operation for data processing from L0 to L1 is to average the pre- and postflight calibrations. That being said, a day to day comparison 
between calibrations in 2014 showed that a single calibration in fact could be substituted with only minor errors for the whole week's campaign.

For detection of trace gases, flights are usually conducted at an altitude of $1 \mathrm{~km}$ above ground level (a.g.l.) to minimize atmospheric attenuation between ground and sensor. The HyTES pixel size at $1 \mathrm{~km}$ a.g.l. is $\sim 2 \mathrm{~m}$. Figure 2 shows an example of a HyTES data hypercube for a flight over Death Valley, California. Radiances in the vertical slice have been atmospherically corrected for the atmospheric transmission and path radiance using an in-scene atmospheric correction approach.

\section{Thermal infrared physics}

The clear-sky radiance measured by a sensor in the TIR spectral region $(7-14 \mu \mathrm{m})$ is a combination of the Earth-emitted radiance, reflected downwelling sky irradiance, and atmospheric path radiance, and is defined as the flux per unit projected area per unit solid angle incident at the sensor. The Earth-emitted radiance is a function of the land surface temperature and spectral emissivity and gets attenuated by the atmosphere on its path to the sensor. The atmosphere also emits radiation, some of which gets scattered up into the path of the sensor directly and called the atmospheric path radiance, while some gets radiated to the surface (irradiance) and reflected back to the sensor-termed the reflected downwelling sky irradiance. Reflected solar radiation in the TIR region is negligible and is not accounted for in forward simulations of at-sensor radiance. One effect of the sky irradiance is to reduce the spectral contrast of the emitted radiance, since the addition of the downward reflected component "fills" in the spectral features from the surface.

\subsection{Theory}

Using Kirchhoff's law, we can write the hemisphericaldirectional reflectance as a function of directional emissivity $\left(\rho_{\lambda}=1-\epsilon_{\lambda}\right)$, and express the at-sensor radiance for a clearsky pixel with no gas plume attenuation ("off-plume"), $\left(L_{\lambda}^{\text {off }}\right)$ as follows:

$L_{\lambda}^{\text {off }}(\theta)=L_{\lambda}^{\text {gnd }} \tau_{\lambda}^{\text {atm }}+L_{\lambda}^{\uparrow}$,

where $\tau_{\lambda}^{\mathrm{atm}}$ is the atmospheric transmittance, $L_{\lambda}^{\uparrow}$ is the atmospheric path radiance, and $L_{\lambda}^{\text {gnd }}$ is the total land leaving radiance:

$L_{\lambda}^{\text {gnd }}(\theta)=L_{\lambda}^{\text {surf }}+\rho_{\lambda} L_{\lambda}^{\downarrow}=\epsilon_{\lambda} B_{\lambda}\left(T_{\mathrm{s}}\right)+\left(1-\epsilon_{\lambda}\right) L_{\lambda}^{\downarrow}$,

where $\lambda$ is the wavelength; $\theta$ the observation angle; $L_{\lambda}^{\text {surf }}$ the Earth-emitted radiance; $\epsilon_{\lambda}$ the spectral surface emissivity; $T_{\mathrm{s}}$ the surface temperature; $L_{\lambda}^{\downarrow}$ the downwelling sky irradiance; $\tau_{\lambda}^{\mathrm{atm}}$ the atmospheric transmittance; $L_{\lambda}^{\uparrow}$ the atmospheric path

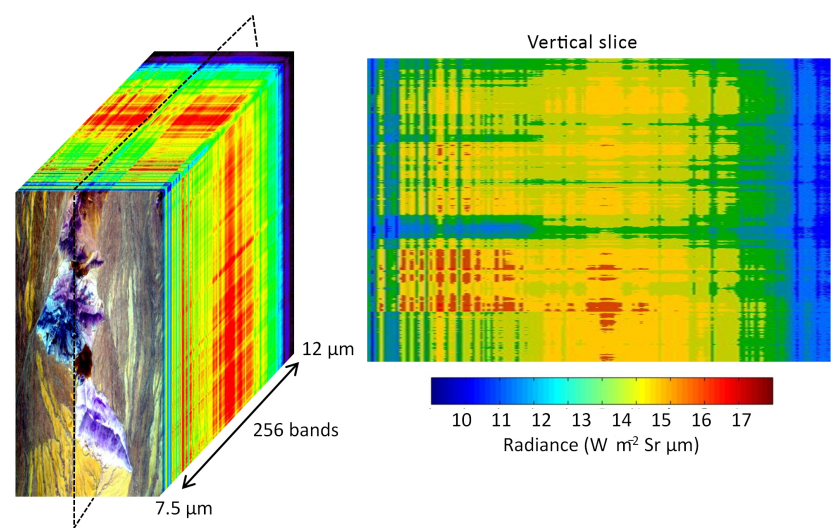

Figure 2. HyTES data hypercube over Death Valley, California. Radiances in the vertical slice have been atmospherically corrected for the atmospheric transmission and path radiance.

radiance; $B_{\lambda}\left(T_{\mathrm{s}}\right)$ the Planck function defined at temperature, $T_{\mathrm{s}}$.

The radiance measured by a sensor for a pixel centered on a gaseous plume ("on-plume") introduces an additional plume thermal emission term, $L_{\lambda}^{\mathrm{p}}$, and a plume transmissivity term, $\tau_{\lambda}^{\mathrm{p}}$ to account for the additional attenuation of the surface radiance:

$L_{\lambda}^{\mathrm{on}}(\theta)=L_{\lambda}^{\mathrm{gnd}} \tau_{\lambda}^{\mathrm{atm}} \tau_{\lambda}^{\mathrm{p}}+L_{\lambda}^{\uparrow}+L_{\lambda}^{\mathrm{p}} \tau_{\lambda}^{\mathrm{atm}}$,

where $L_{\lambda}^{\mathrm{p}}=\epsilon_{\lambda}^{\mathrm{p}} B_{\lambda}\left(T_{\mathrm{p}}\right)$ is the gas plume emission term, $T_{\mathrm{p}}$ is the plume temperature, and $\epsilon_{\lambda}^{\mathrm{p}}$ the plume emissivity. An illustration depicting these components for an observation over a gaseous plume is shown in Fig. 3. These terms can be simplified using some physics-based assumptions. The weak plume transmissivity, $\tau_{\lambda}^{\mathrm{p}}$, is given by Beer's law:

$\tau_{\lambda}^{\mathrm{p}}=e^{-n_{o} b_{\lambda}}$,

where $n_{o}$ is the gas column density and $b_{\lambda}$ is the gas absorbance spectra ("plume signature"), usually extracted from the HITRAN database for the relevant gas constituent. If we assume the gas plume is optically thin and plume absorbance, $\left(n_{o} b_{\lambda}\right)$, is small, we can approximate Eq. (4) with a Taylor expansion:

$\tau_{\lambda}^{\mathrm{p}} \approx 1-n_{o} b_{\lambda}$.

The Beer-Lambert law can then be used to write the transmittance as a function of the gas plume effective emissivity:

$\epsilon_{\lambda}^{\mathrm{p}}=1-\tau_{\lambda}^{\mathrm{p}} \approx n_{o} b_{\lambda}$.

Substituting Eq. (6) into Eq. (3) and rearranging terms yields an equation describing the total at-sensor radiance for an observation centered on a gaseous plume pixel:

$L_{\lambda}^{\mathrm{on}}(\theta)=\left[L_{\lambda}^{\mathrm{gnd}} \tau_{\lambda}^{\mathrm{atm}}+L_{\lambda}^{\uparrow}\right]+n_{o} b_{\lambda} \tau_{\lambda}^{\mathrm{atm}}\left[B_{\lambda}\left(T_{\mathrm{p}}\right)-L_{\lambda}^{\text {gnd }}\right]$. 


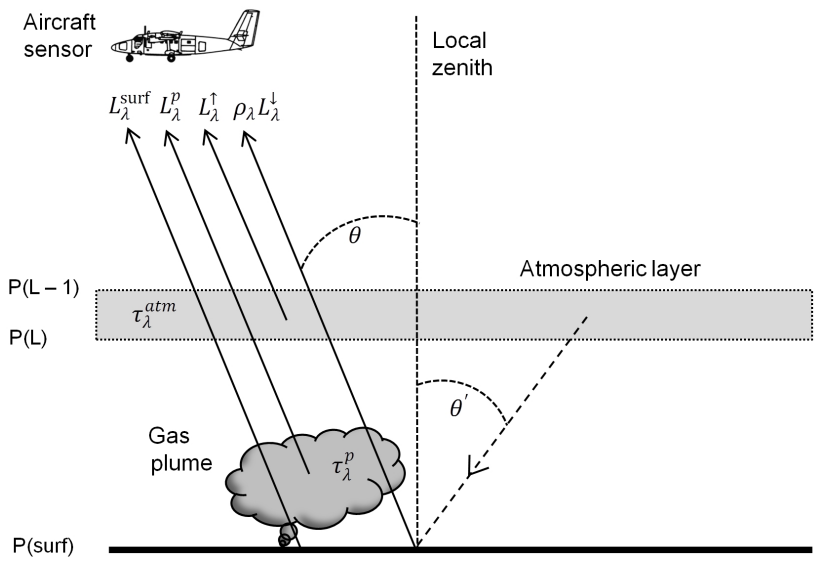

Figure 3. Illustration depicting various components of thermal infrared radiative transfer with a gaseous plume, where $L_{\lambda}^{\text {surf }}$ is the Earth-emitted radiance, $L_{\lambda}^{\mathrm{p}}$ is the plume thermal emission term, $L_{\lambda}^{\uparrow}$ the atmospheric path radiance, $\rho_{\lambda} L_{\lambda}^{\downarrow}$ the reflected downwelling radiance, $\tau_{\lambda}^{\mathrm{atm}}$ the atmospheric transmittance, $\tau_{\lambda}^{\mathrm{p}}$ the plume transmittance, $\theta$ the observation angle, and $\mathrm{P}(*)$ the pressure level.

The first term on the right-hand-side of Eq. (7) describes the off-plume radiance, $L_{\lambda}^{\text {off }}$ (background, or "clutter"), while the second term consists of the plume signature, $b$, multiplied by the plume strength, which includes the column density, $n_{o}$, multiplied by the thermal contrast term, $\left[B_{\lambda}\left(T_{\mathrm{p}}\right)-L_{\lambda}^{\mathrm{gnd}}\right]$. Examination of this term indicates that the detection of gaseous plumes in the TIR requires a finite thermal contrast between the surface and the plume, otherwise the plume strength term approaches zero. To solve Eq. (7), knowledge of the surface temperature of the background, the temperature of the gas plume, the surface emissivity of the background, and the atmospheric terms $\tau_{\lambda}^{\text {atm }}$ and $L_{\lambda}^{\uparrow}$ is needed. The atmospheric terms are estimated using an atmospheric correction technique described in the next section, and are usually fairly constant across an image at the scale of a few kilometers depending on variability in atmospheric water vapor.

\subsection{In-Scene Atmospheric Correction (ISAC) methods}

The spectral radiance in Eq. (1) will include atmospheric emission, scattering, and absorption by the Earth's atmospheric constituents. In order to isolate the land-leaving surface radiance and separate the surface temperature and spectral emissivity terms, these atmospheric effects need to be removed from the observation. For on-plume pixel observations, the atmospheric compensation isolates the landleaving radiance contribution in addition to reducing the wavelength dependence of the plume strength, which is the difference between radiance emitted by plume and ground as expressed in Eq. (7). The success of the atmospheric correction depends on the accurate characterization of the atmospheric state that is input into the radiative transfer model

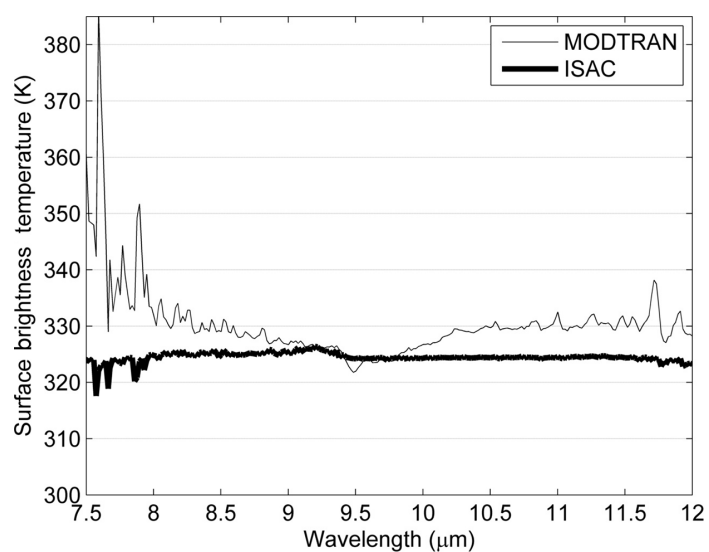

Figure 4. An example of surface brightness temperature spectra from HyTES after atmospheric correction using the RTM approach with MODTRAN (gray line), and the ISAC approach (black line). With a successful atmospheric correction we expect a nearly constant temperature across all bands, which is achievable with the ISAC approach but not with MODTRAN below $8 \mu \mathrm{m}$ and above $11.5 \mu \mathrm{m}$ because of misregistrations between HyTES data and MODTRAN.

(RTM) e.g., MODTRAN (Berk et al., 2005). Independent atmospheric profiles of temperature, water vapor, and other gas constituents (e.g., ozone) are input to the RTM to obtain the atmospheric transmittance, path radiance, and sky irradiance terms. Once the residual effects of the atmosphere have been removed from the observed radiance the surface properties can be obtained.

For multispectral data, where the bands are typically not strongly affected by the atmosphere the RTM approach works satisfactorily, but for hyperspectral data the RTM approach is more challenging when bands are situated in strong atmospheric absorption features and if output model data from the RTM are not accurately spectrally registered with the observed data, then the solution may be unstable. This instability primarily arises because (1) methods used in the RTM to interpolate hyperspectral absorbances introduce error, (2) the sensor's spectral responses functions are not precisely defined, and (3) band-to-band registration issues result in model error. In these cases even small misregistrations between the observed and modeled data near strong absorption lines will amplify instead of reduce the effects of atmospheric attenuation, making correction of the radiance spectrum very difficult. To address these issues, an in-scene atmospheric correction (ISAC) approach was developed for the SEBASS airborne hyperspectral sensor (Young et al., 2002). The main advantage of the ISAC method is that atmospheric correction is accomplished using the hyperspectral data itself without the need for external atmospheric profiles or an RTM. In addition, the issue of spectral band misregistrations is eliminated. An example of this is shown in Fig. 4 where surface brightness temperature spectra are shown from HyTES after atmospheric correction using the RTM approach with MOD- 
TRAN (gray line), and the ISAC approach (black line). With a successful atmospheric correction we expect a nearly constant temperature across all bands, which is achievable with the ISAC approach but not with MODTRAN below $8 \mu \mathrm{m}$ and above $11.5 \mu \mathrm{m}$ because of band-to-band misregistrations between HyTES data and MODTRAN in the presence of higher water vapor absorption regions.

ISAC relies on finding gray bodies in a given scene with emissivity close to 1 across all bands, $\epsilon_{\lambda} \sim 1$ (e.g., water, dense vegetation, ice, snow). Then, the observed radiance in Eq. (1) can be written as a linear function with an independent variable, $B_{\lambda}\left(T_{\mathrm{s}}\right)$, and with slope $\tau_{\lambda}^{\text {atm }}$ and $y$ intercept $L_{\lambda}^{\downarrow}$ as follows:

$L_{\lambda}^{\text {off }}=\left[B_{\lambda}\left(T_{\mathrm{s}}\right) \tau_{\lambda}^{\mathrm{atm}}+L_{\lambda}^{\uparrow}\right]$.

Theoretically, the atmospheric parameters $\tau_{\lambda}^{\text {atm }}$ and $L_{\lambda}^{\uparrow}$ can then be found by simple linear regression by plotting $L_{\lambda}^{\text {off }}$ vs. $B_{\lambda}\left(T_{\mathrm{S}}\right)$ for all pixels on a scene for a given wavelength. We found that using the maximum brightness temperature "most hits" method as proposed by Young et al. (2002) resulted in pixels consisting of different types of soils in agricultural environments, with emissivities $<0.95$ often being included in the fitting procedure. This was verified by comparing these pixels with emissivity information from the ASTER Global Emissivity Database (ASTER GED) at $\sim 100 \mathrm{~m}$ spatial resolution (Hulley et al., 2015). Misclassification was usually worse over scenes with high temperatures, where bare soils exhibit near-blackbody-like behavior and are confused with true gray bodies such as dense vegetation. These non-graybody pixels violate the intrinsic assumptions of the ISAC method, leading to errors in the fitting procedure.

To address this issue we developed a spectral variance approach in which the spectral variance in observed radiance was calculated for each pixel and only those pixels with low variance (e.g., a threshold set at less than $8 \mathrm{~W} \mathrm{~m}^{-2}$ ) were assumed to be gray-body pixels suitable for use in the fitting procedure. Using this approach resulted in a very good match with gray bodies classified according to the ASTER GED emissivities. The spectral variance approach is a good assumption for low-altitude flights (1 km a.g.l.) in which observed radiance is still representative of underlying surface spectral features, and also because the emissivity spectra of gray-body surfaces such as vegetation, snow, ice, and water are pseudo-invariant in the $8-12 \mu \mathrm{m}$ range.

A large fraction of the HyTES target sites including those over a few key methane hotspots (e.g., Kern River oil field) were flown over bare regions containing very few gray-body pixels (e.g., vegetation, water) and an alternative ISAC approach had to be developed. In this approach, termed the ISAC-ASTER method, emissivity information from the five ASTER GED TIR bands from 8 to $12 \mu \mathrm{m}$ were used directly in the ISAC fitting procedure instead of relying on the blackbody assumption. ASTER GED emissivities at $100 \mathrm{~m}$ spatial resolution were first geolocated and interpolated onto the

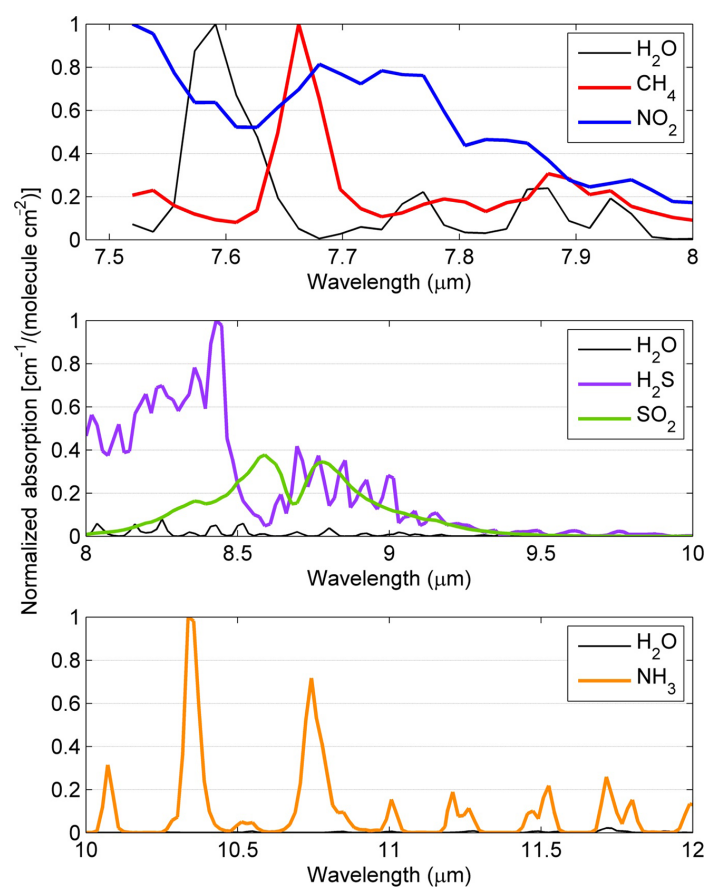

Figure 5. Normalized absorption spectra of $\mathrm{H}_{2} \mathrm{O}, \mathrm{CH}_{4}, \mathrm{NO}_{2}, \mathrm{H}_{2} \mathrm{~S}$, $\mathrm{SO}_{2}$, and $\mathrm{NH}_{3}$ extracted from the HITRAN 2012 database and convolved to the HyTES spectral response functions displayed in different wavelength ranges in the thermal infrared from 7.4 to $12 \mu \mathrm{m}$.

HyTES scene and then a principal component (PC) regression approach (Borbas et al., 2007) was used to extend the 5 ASTER band emissivities to the 256 HyTES bands from 7.4 to $12 \mu \mathrm{m}$ (Hulley et al., 2014).

\section{Plume detection methodology}

The problem of identifying plumes from trace gas species in hyperspectral data is based on a set of linear algebraic expressions that are used to find signals in nonlinear noisy (cluttered) background data (Funk et al., 2001; Theiler and Foy, 2006). The challenge is to condense a set of nonlinear results, radiative transfer through the atmosphere, and hyperspectral data, into a linear signal-in-noise problem. This approximation becomes easier with weaker plumes that are close to being linear in their effect on the observed signal. The problem can further be simplified by transforming the radiance data to atmospherically compensated brightness temperatures. Several "matched filter" formulations have been developed, each with a basic goal of generating a weighting function based on a given specific target gas signature, and producing an image using the observed hyperspectral data in which the intensity of the image correlates with the presence of the desired signature assumed to be distinct from the background covariance. Figure 5 shows normalized absorption spectra extracted from the HITRAN database of various trace gases including $\mathrm{H}_{2} \mathrm{O}, \mathrm{CH}_{4}, \mathrm{NO}_{2}, \mathrm{H}_{2} \mathrm{~S}, \mathrm{SO}_{2}$, and $\mathrm{NH}_{3}$ 
in different wavelength ranges and convolved to the HyTES spectral response functions. The strongest $\mathrm{CH}_{4}$ absorption feature at $7.68 \mu \mathrm{m}$ has minimal overlap with strong water vapor absorption features on either side at 7.6 and $7.78 \mu \mathrm{m}$, allowing higher signal-to-noise detection during humid conditions. The strongest features of $\mathrm{H}_{2} \mathrm{~S}$ and $\mathrm{SO}_{2}$ are in the 8-9 $\mu \mathrm{m}$ range, while ammonia has distinct spectral features in the $10-11 \mu \mathrm{m}$ window range in which $\mathrm{H}_{2} \mathrm{O}$ absorption is minimal. A key advantage of HyTES is its higher spectral resolution with respect to other airborne hyperspectral TIR sensors (see Table 1), which results in higher sensitivity for detection of trace gas species, particularly those gases with sharp spectral features such as $\mathrm{H}_{2} \mathrm{~S}$ and $\mathrm{NH}_{3}$.

\subsection{Clutter matched filter (CMF)}

Starting with a data cube, $L$ of hyperspectral thermal infrared data, contains an image of $N$ columns by $n$ rows, where the columns denote the number of pixels in a given image, and $n$ denotes the number of spectral channels. The goal is to find a wavelength-dependent spectral signature, $b$, which is assumed to be linearly superimposed on the background signal or clutter. This can be expressed by the following equation:

$r=\propto b+c$,

where $r$ is the total radiance and can be modeled as a linear combination of signal, $\propto b$, where $\propto$ is the strength of a plume signature, $b$, and $c$ is a noise term that contains both sensor noise and scene clutter. The plume signature $b$ is usually expressed in terms of absorbance, and is typically extracted from the HITRAN database and convolved to the sensor's spectral response. Figure 5 shows an example of $\mathrm{CH}_{4}$ and $\mathrm{H}_{2} \mathrm{O}$ normalized absorbance spectra in the 7.5-8.1 $\mu \mathrm{m}$ range convolved to the HyTES spectral response. The scene clutter contains radiance contributions from the ground and atmosphere, and is defined as noise with cross-spectral correlations. These spectral cross correlations can be written in terms of a covariance matrix, $\mathbf{K}$ :

$\mathbf{K}=\left\langle c c^{T}\right\rangle=\frac{1}{N} L L^{T}$.

Given the covariance of the background clutter, $\mathbf{K}$, we can then find the optimum filter vector, $\boldsymbol{q}$, as follows:

$\boldsymbol{q}=\frac{\mathbf{K}^{-1} b}{\sqrt{b^{T} \mathbf{K}^{-1} b}}$,

where $\boldsymbol{q}$ is normalized such that the variance, $\boldsymbol{q}^{T} \mathbf{K} q=1$. This ensures that in the absence of the signal, the matched filter image will have a variance of 1 . The final clutter matched filter (CMF) image, is calculated by applying $\boldsymbol{q}$ to the original data cube of radiance:

$\mathrm{CMF}=\boldsymbol{q}^{T} L$.
In order to minimize the effects of striping and other noise in the data, the CMF is calculated in a matrix column-wise fashion (along-track) for a given data swath. The CMF result for each column is then demeaned by subtracting the sample mean from each observation and dividing by the standard deviation using all pixels on the scene. This results in a mean CMF of zero and standard deviation of 1 for each column of data. The final CMF will produce an image in which the intensity correlates with the desired plume signature as defined by $b$. Values that are classified as outliers in the final CMF are strong evidence for the presence of the desired signature, and their significance quantified by number of sigmas of the distribution; however this metric is only valid if the matched filter distribution is Gaussian (Funk et al., 2001).

We can further define a dimensionless quantity called the signal clutter ratio (SCR), which is computed by applying the signal filter vector in Eq. (11) to the target plume signature, $b$ :

$\mathrm{SCR}=\boldsymbol{q}^{T} b$.

The SCR can be used as a metric for evaluating the strength of the desired target signal above background clutter, or the radiance emitted by other targets in the field of view. Usually the optimally derived CMF in Eq. (12) will maximize the SCR values derived in Eq. (13). SCR values are normalized from [ $\left.\begin{array}{ll}0 & 1\end{array}\right]$ and values closer to 1 indicate higher confidence in the presence of the desired gas target pixels in the image data.

\subsection{Plume dilation algorithm}

The CMF detection algorithm for HyTES is optimized to detect only the strongest $\mathrm{CH}_{4}$ sources using a five-step process. The algorithm is designed to minimize false positives while enhancing plume structure around the strongest sources using a plume dilation algorithm. This algorithm is used to provide qualitative information to help attribute emissions to specific source types and source locations. The CMF can also be tuned to detect more diffuse $\mathrm{CH}_{4}$ enhancements that could be the result of advection further downwind from a specific source. For example, ground surveys have shown that some of the highest concentrations are found downwind at significant distances (hundreds of meters) from the original source (Leifer, 2014). However, lowering the CMF threshold comes at the cost of increasing the likelihood of false positives in the final image.

Once a binary image of the strongest plume pixels is generated from thresholding the CMF result, a dilation algorithm is used to enhance the structure and edges of the plume (Broadwater et al., 2008). The binary image is first dilated within a 2-by-2 pixel neighborhood and then multiplied by the original CMF detection image. This results in an image with modified CMF values in the neighborhood immediately around the original plume pixels. A slightly lower detection threshold is then applied to the new detection image, result- 
ing in a binary image that is again dilated within a 2-by-2 pixel neighborhood. This process repeats until a minimum detection threshold is reached based on the initial threshold set. After each iteration, a contiguity test is applied that removes any pixels with fewer than two neighbors. The result is an adaptive plume-growing algorithm that finds the gas plume edges immediately surrounding the strongest gas plume pixels, while simultaneously reducing any false positives and noise.

A number of different configurations and thresholds were tested, which resulted in a final set of steps that both optimized the presence of the strongest gas plume pixels and simultaneously reduced any false positives and noise. The results of the three primary steps are demonstrated in Fig. 6, which shows a sequence of two methane plumes detected over the Kern River oil field (top panels) and Four Corners (bottom panels).

\section{Results of field testing}

In this section we summarize results of field tests that evaluated the performance of the CMF plume detection and imaging capability for different gases, key emission sectors, and a variety of surface conditions. This represents a small subset of a 2-year program, spanning multiple seasons that ranged from test facilities in Wyoming, to oil and gas fields in Colorado and New Mexico, to California's San Joaquin Valley, and to the Los Angeles Basin.

\subsection{Anthropogenic methane}

While HyTES has the ability to detect multiple trace gases, much of this work focused on improving understanding of atmospheric methane given its high importance both for scientists and decision-makers as a key climate-forcing greenhouse gas and ozone precursor. The atmospheric growth rate of methane and controlling emission sources remains highly uncertain at regional to global scales (Dlugokencky et al., 2009; Kirschke et al., 2013; Miller et al., 2014; Rigby et al., 2008). Future changes in surface temperatures and precipitation have the potential to dramatically alter natural methane fluxes from large Arctic reservoirs (Damm et al., 2010; Kort et al., 2012) and tropical wetlands (Dlugokencky et al., 2009), while transformational changes in anthropogenic emissions from fossil fuel production threaten to further increase atmospheric methane abundance (Larsen et al., 2015). Examples of anthropogenic sources of methane include the natural gas and oil supply chains (production, storage, transmission, distribution, consumption), agricultural activities (enteric fermentation, manure management, rice cultivation), landfills, coal mining, stationary and mobile combustion, and wastewater treatment (Thomas and Zachariah, 2012). This work focuses on anthropogenic point source emitters rather than more diffuse area sources, given that the former are
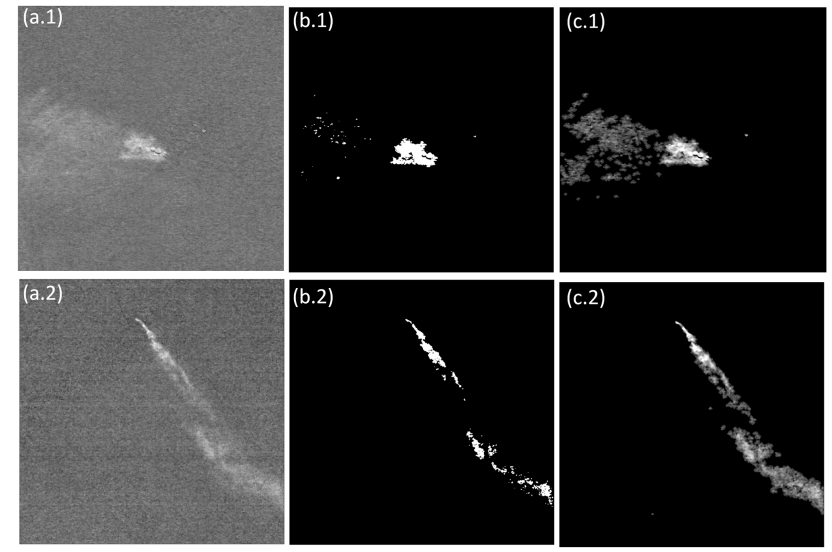

Figure 6. An example of the three-step plume detection and enhancement algorithm for two methane plumes detected over the Kern River oil field (top panels) and Four Corners (bottom panels), $(\mathbf{a . 1}, \mathbf{2})$ original CMF normalized from [0 1] where brightest pixels are associated with the presence of the target gas plume, $(\mathbf{b . 1}, \mathbf{2})$ a threshold is set on the CMF using an interquartile range with weight set to 2.5 , and $(\mathbf{c . 1}, 2)$ final plume image after a plume dilation algorithm is implemented (see text for details).

both uncertain and more readily detectable with TIR imaging spectroscopy.

Detection of methane from infrared measurements is possible due to the absorption from strong rotational-vibrational transitions $(\nu 4)$ in the $7.3-8 \mu \mathrm{m}$ range that have sufficient separation from the strong water vapor band centered at $6.3 \mu \mathrm{m}$ (see Fig. 5). Hyperspectral satellite sensors like the Infrared Atmospheric Sounding Interferometer (IASI) (Aires et al., 2002), the Tropospheric Emission Spectrometer (TES) (Beer, 2006), and the Atmospheric Infrared Sounder (AIRS) (Tobin et al., 2006) are able to take advantage of these absorption characteristics of methane, however are limited by their coarse spatial resolutions ( $10 \mathrm{~km}$ or more) and insensitivity to near-surface concentrations due to sensor saturation issues. Airborne hyperspectral TIR sensors such as HyTES and others detailed in Table 1 have the imaging capability of detecting methane emission sources at the scale of a few meters, allowing improved characterization of individual point sources towards better understanding of their distribution.

\subsubsection{Oil production example: Kern River oil field}

HyTES flew a set of flight lines over 4 days covering the extent of the Kern River and Kern Front oil fields during June 2014 and February 2015. This is a relatively large $\left(44 \mathrm{~km}^{2}\right)$ oil field in the greater Bakersfield area of California, densely populated with production wells, storage, processing, and distribution infrastructure. Most of the production in this area relies on thermal enhanced oil recovery technologies (e.g., steam flooding). This often results in a mix of $\mathrm{CH}_{4}$ gas and a 


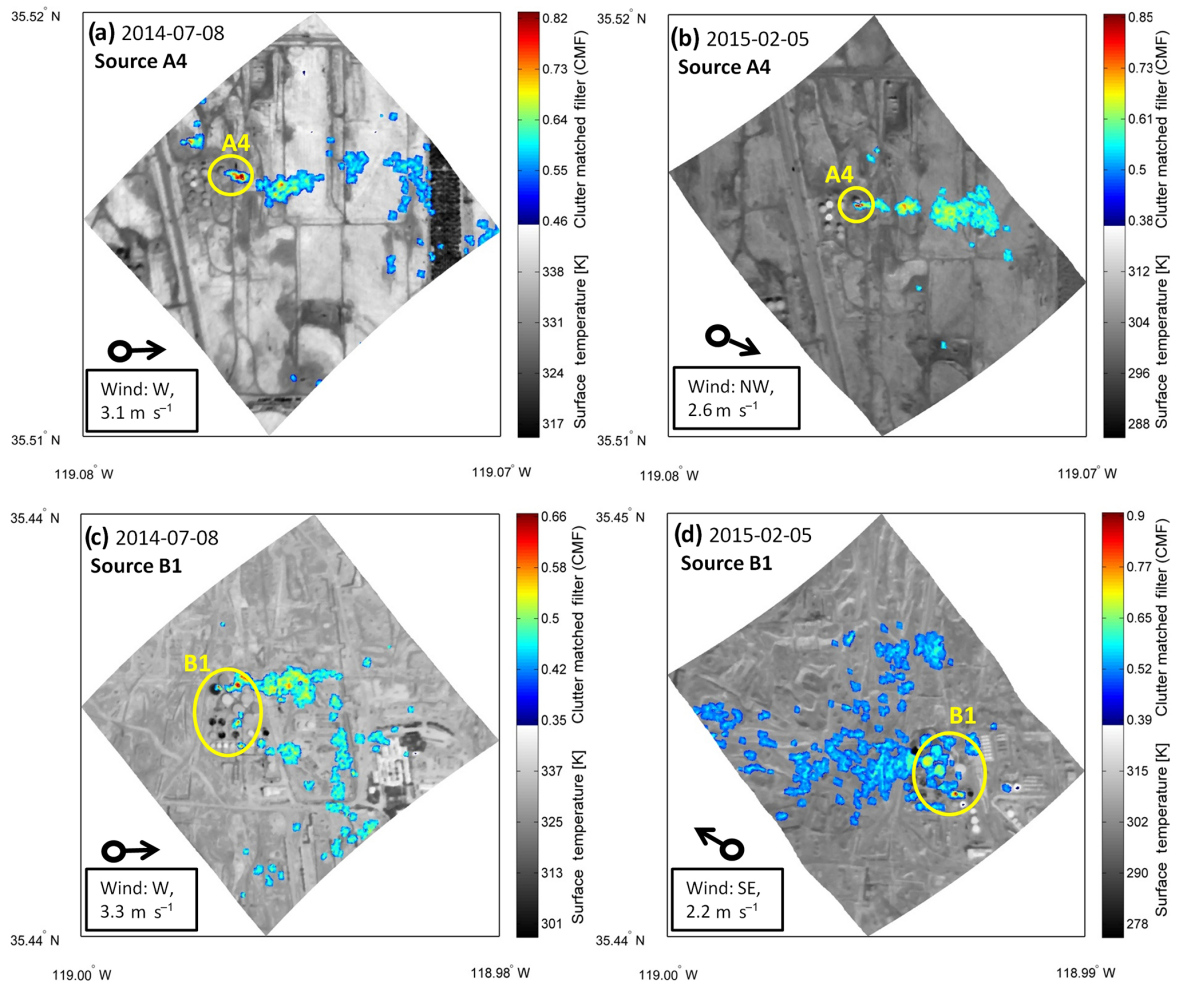

Figure 7. Examples of persistent methane plumes detected by HyTES over oil condensate storage tanks in the Kern Front and Kern River oil fields near Bakersfield, California. Sources A4 in panels (a) and (b), and B1 in panels (c) and (d) were detected during July 2014 and February 2015. Plume enhancements are shown in color using the CMF method overlayed on a surface temperature image.

high-temperature steam "cloud" with high water vapor loading, which has the potential for confusing the matched filter for methane detection resulting in false positives. Together with the complex terrain and often strong winds this offered a challenging test of the HyTES detection capability.

HyTES surveyed the Kern River oil field on 8 July 2014 with nine flight lines (each $1 \mathrm{~km}$ wide by $10 \mathrm{~km}$ long), 10 flight lines on 5 February 2015, and an additional 10 flight lines on 8 February 2015 at an altitude of $1 \mathrm{~km}$ a.g.l. with a pixel resolution of $\sim 2 \mathrm{~m}$. The 2015 flight campaign was used to identify persistent sources, to refine the atmospheric correction and CMF visualization algorithms, and to identify priority targets for follow-up quantitative retrieval analysis with a more computationally intensive algorithm (Kuai et al., 2016). Using the CMF algorithm with a target spectrum of methane, multiple individual sources of methane were identified over the Kern River field. A number of these sources were persistent with detections in July 2014 and February 2015. Repeated detections over time provide confidence in the detection algorithm, especially when plume shapes and trajectories correspond well with wind vector and speed observations from the same day. Examples of two of these persistent plume sources are illustrated in Fig. $7 \mathrm{a}$ and $\mathrm{b}$ for source A4 and Fig.7 c and d for source B1. Each panel shows the $\mathrm{CMF}$ for $\mathrm{CH}_{4}$ overlayed on a surface temperature im- age derived from the HyTES long-wave TIR data. Higher intensity CMF values in red/yellow are indicative of higher concentration of the target gas $\left(\mathrm{CH}_{4}\right)$. Spatial variations in the plume shapes are caused primarily from fluctuations in wind direction and speed, and also turbulence. The detected plumes all had high SCR values ranging from 0.75 to 0.85 and the shapes of all plumes were consistent with the wind direction derived from local meteorological measurements. (Note the different wind direction and plume trajectories for source B1.)

To illustrate the ability to distinguish methane from water associated with steam flooding in the Kern River field, Fig. 8 shows an example of HyTES observed brightness temperature spectrum in the $7.5-8 \mu \mathrm{m}$ range extracted from an on-plume and off-plume pixel for a plume detected over a well pad. The right image in Fig. 8 shows the CMF overlay result with the on- and off-plume pixels highlighted. The off-plume pixel was chosen to be similar in spectral shape and magnitude as the on-plume pixel, except without the evidence of methane absorption. Both spectra clearly show the strong water absorption feature in the 7.55-7.76 and 7.85$7.9 \mu \mathrm{m}$ regions from ambient atmospheric water vapor loadings, while the distinctive $\mathrm{CH}_{4}$ absorption feature between 7.65 and $7.7 \mu \mathrm{m}$ is only seen for the on-plume pixel with a difference of $\sim 10 \mathrm{~K}$ from the off-plume spectra. Figure 8 

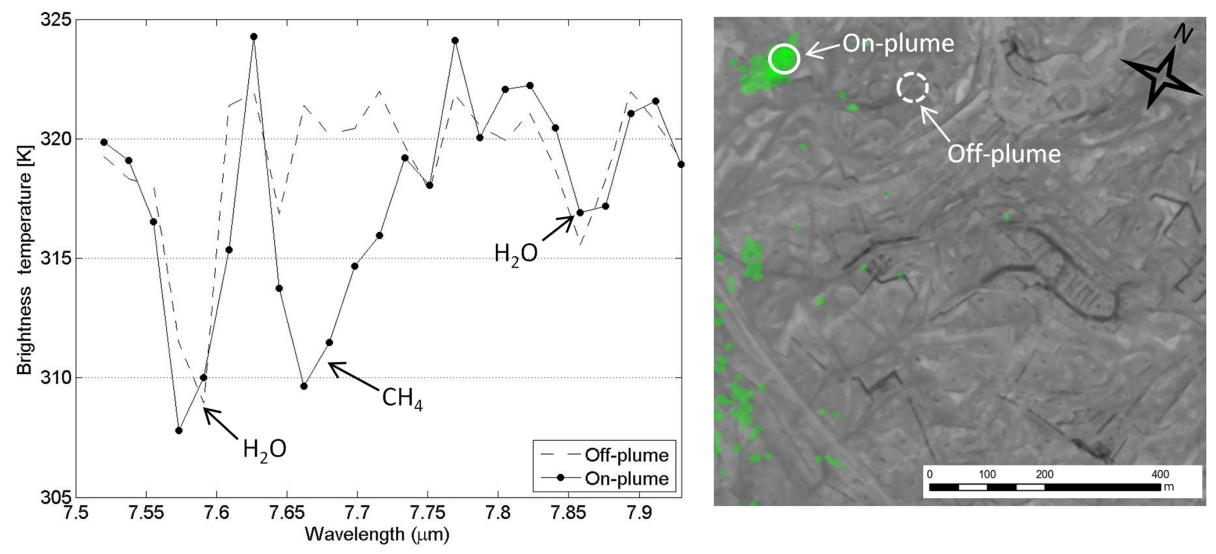

Figure 8. HyTES brightness temperature spectra (left) from 7.5 to $8 \mu \mathrm{m}$ for an on-plume and off-plume pixel indicated in the CMF temperature overlay (right) for a plume over the Kern River oil field in July 2014. The presence of $\mathrm{H}_{2} \mathrm{O}$ features in both the on-plume and off-plume pixels but only $\mathrm{CH}_{4}$ in the on-plume pixel indicates the latter detection is not a false positive.

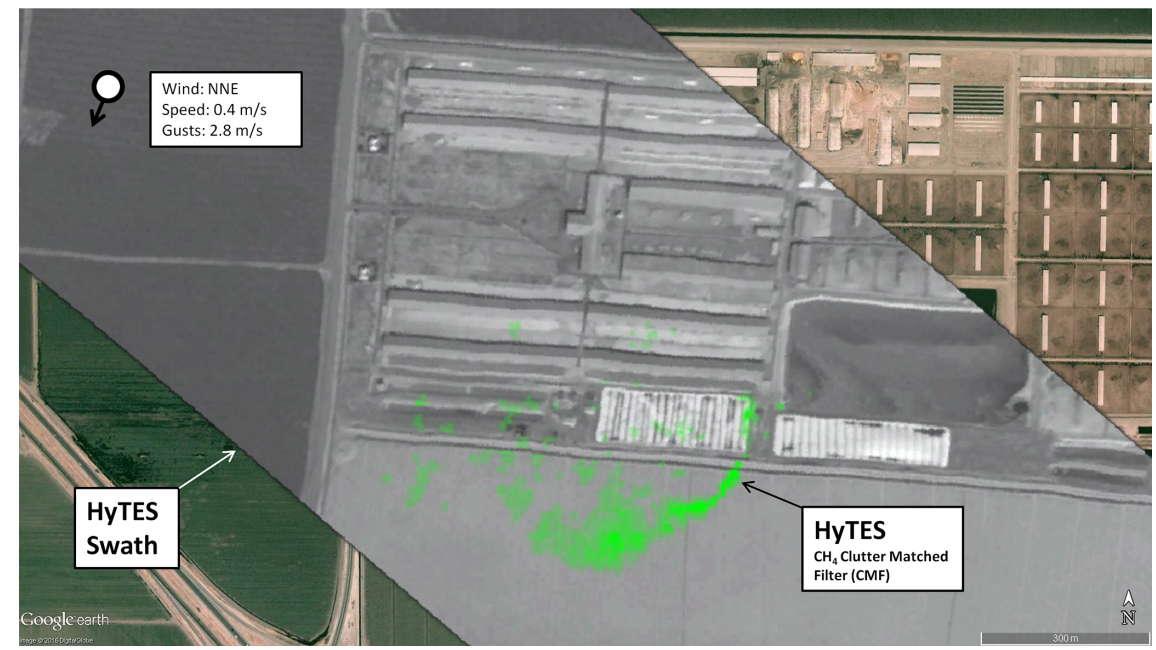

Figure 9. HyTES-detected methane plumes over a dairy farm in the San Joaquin Valley, California, during February 2015 displayed in Google Earth with the methane plume in green overlayed on HyTES grayscale surface temperature retrieval. The dispersion of the detected plume is consistent with wind measurements in the local area (from NNE at $0.4 \mathrm{~m} \mathrm{~s}^{-1}$ with gusts to $2.8 \mathrm{~m} \mathrm{~s}^{-1}$ ).

clearly shows a distinct separation between the $\mathrm{H}_{2} \mathrm{O}$ and $\mathrm{CH}_{4}$ absorption features for the on-plume pixel due to the high spectral resolution of HyTES data $(18 \mathrm{~nm}$ spectral resolution).

\subsubsection{Manure management example: Bakersfield dairies}

Methane emissions associated with livestock represent the largest source of methane emissions in California; enteric fermentation contributes about $35 \%$, and manure management about $30 \%$ of the total budget (EPA, 2011). In addition to methane, ammonia, hydrogen sulfide, and other oxygenated organic compounds are emitted from management of animal waste (manure). At many dairies in the SJV, waste is flushed from animal houses into waste lagoons and stor- age ponds for storage and intermediate treatment (Ham and DeSutter, 2000; Liang et al., 2002; Ro et al., 2013).

HyTES conducted flights over dairy farms in the vicinity of Bakersfield during July 2014 and February 2015. Using the CMF method, HyTES identified methane source emissions from a number of different dairy farms in the southern Bakersfield dairy region that were concentrated primarily over anaerobic lagoons. Figure 9 shows an example of methane detected over a dairy from a HyTES flight on 8 February 2015. A section of the HyTES swath ( $\sim 2 \mathrm{~km}$ wide) is shown as grayscale temperature image with methanedetected pixels overlayed in green. A distinct and localized methane source can be seen in the vicinity of a covered anaerobic lagoon in Fig. 9, and the dispersion of the detected 


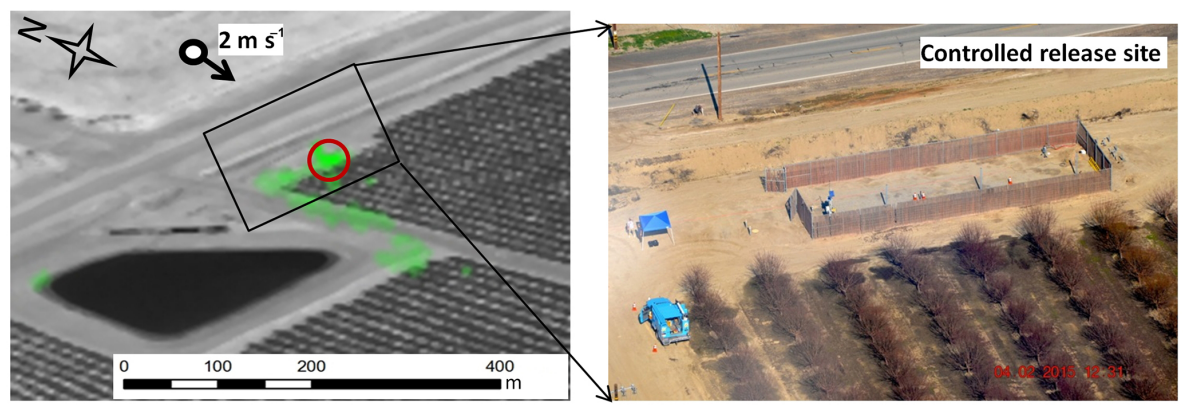

Figure 10. Example of HyTES-detected methane (green) with overlay on grayscale surface temperature (left) at the natural gas controlled release site (inset photograph). Detected methane in the HyTES image is displayed in green with the higher intensity color corresponding with highest concentration of methane at the release point circled in red.

Table 2. Results from a controlled release experiment on 28 April 2015 where natural gas was released from a $\sim 2 \mathrm{~m}$ high stack at a pressureregulating station near Bakersfield, California. Aircraft altitude, fluxes (SCFH is the standard cubic feet per hour), wind speed, pixel size, and maximum (dMax) and total values (dTotal) of $\mathrm{CH}_{4}$ calculated from the clutter matched filter $(\mathrm{CMF})$ and $\mathrm{CH}_{4}$ retrieved concentration values $(\mathrm{ppm})$ are shown, where $\mathrm{dMax}=\left[\max \left(\mathrm{CH}_{4}\right)-\mathrm{BKG}\right]$, and dTotal $=\left[\mathrm{Sum}\left(\mathrm{CH}_{4}\right)-\mathrm{BKG}\right]$, where $\mathrm{BKG}$ is the average $\mathrm{CH}_{4}$ background value of pixels in which no plume was detected.

\begin{tabular}{lcrrrrrr}
\hline & \multicolumn{3}{c}{} & \multicolumn{2}{c}{ CMF results } & \multicolumn{2}{c}{ Retrieval results } \\
\hline $\begin{array}{l}\text { Altitude } \\
(\mathrm{m})\end{array}$ & $\begin{array}{c}\text { Fluxes } \\
\left(\mathrm{SCFH}, \mathrm{kg} \mathrm{h}^{-1}\right)\end{array}$ & $\begin{array}{r}\text { Wind speed } \\
\left(\mathrm{m} \mathrm{s}^{-1}\right)\end{array}$ & $\begin{array}{r}\text { Pixel size } \\
(\mathrm{m})\end{array}$ & $\begin{array}{r}\text { dMax } \\
(\% \text { error })\end{array}$ & dTotal & dMax (\% error) \\
$(\mathrm{ppm})$ & $\begin{array}{r}\text { dTotal } \\
(\mathrm{ppm})\end{array}$ \\
\hline 500 & 1000,20 & 1.96 & 0.782 & $0.55(4.5)$ & 158.15 & $0.98(12)$ & 6.24 \\
500 & 500,10 & 2.30 & 0.754 & $0.49(2.8)$ & 133.39 & $0.93(21)$ & 3.64 \\
500 & 250,5 & 1.94 & 0.785 & $0.27(6.1)$ & 66.56 & $0.5(18)$ & 1.29 \\
\hline
\end{tabular}

plume is consistent with wind measurements in the local area (from NNE at $0.5-3 \mathrm{~m} \mathrm{~s}^{-1}$ ).

\subsubsection{Controlled release experiment}

On 28 April 2015, we worked with Pacific Gas and Electric to conduct a controlled release of natural gas from one of their pressure-regulating stations near Bakersfield, California. Gas was released at three flux rates: 250,500 , and 1000 standard cubic feet per hour (SCFH) $(5,10$, and $20 \mathrm{~kg}$ $\mathrm{CH}_{4} \mathrm{~h}^{-1}$ ), with a control accuracy of $\sim 10 \%$. The test lasted for about $3 \mathrm{~h}$ around solar noon, during which a total of 14 HyTES overpasses were conducted at a flight altitude of $\sim 500 \mathrm{~m}$. Ground measurements included a weather station and in situ gas analyzers sampling methane mixing rations $1 \mathrm{~m}$ above the release point and mobile transects of the downwind plume using an automobile. The goal of the experiment was to establish a minimum threshold of detection for the HyTES instrument based on a range of flux rates, and better understand the correlations between the CMF and concentration retrieval results.

Figure 10 shows an example of HyTES-detected methane over the controlled release site (shown in photograph) at 19:38 UTC. In the image, higher intensity green pixels correspond to higher methane mole fractions beneath the HyTES aircraft. The brightest green pixels (red circle) indicate the approximate location of the release point, while lower intensity pixels can be seen advecting down the road in the southerly direction, which is consistent with the wind direction measured nearby at this time $\left(2 \mathrm{~m}^{-1}\right.$ at $\left.20^{\circ}\right)$.

We also show results from the HyTES $\mathrm{CH}_{4}$ quantitative retrieval algorithm (Kuai et al., 2016) in Table 2 and Fig. 11. The quantitative retrieval algorithm was developed and adapted from the algorithm used for retrieving trace gases from the Tropospheric Emission Spectrometer (TES) on board the Aura Satellite. Using HyTES radiance spectra in the 7.5 to $9.2 \mu \mathrm{m}$ range, the HyTES $\mathrm{CH}_{4}$ quantitative algorithm has been used to retrieve methane partial column mole fractions with a total error of approximately $20 \%$ using uncertainties determined primarily from instrument noise and spectral interferences from air temperature, surface emissivity, and atmospheric water vapor (Kuai et al., 2016).

Table 2 shows details of the HyTES flight altitude, $\mathrm{CH}_{4}$ flux released, wind speed, pixel size, and values of the maximum (dMax) and total accumulated (dTotal) values estimated from the CMF (unitless) and concentration retrieval (ppm) algorithms. The dMax value of the quantitative retrieval represents the maximum methane detection above background calculated for pixels in the immediate vicinity of the release point; $\mathrm{dMax}=\max \left(\mathrm{CH}_{4}\right)-\mathrm{BKG}$, where $\mathrm{BKG}$ is the average methane background retrieval located away 

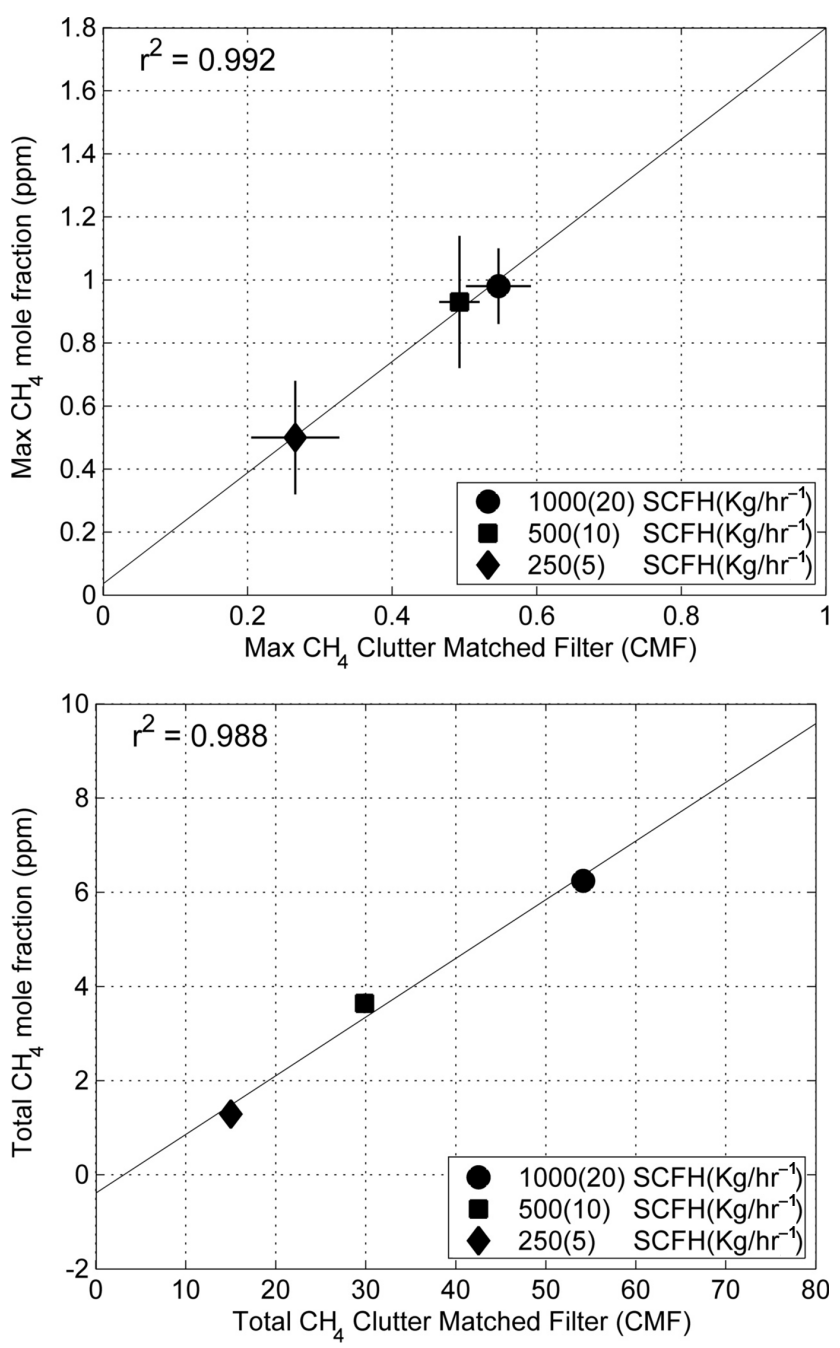

Figure 11. Scatter plots of maximum and total $\mathrm{CH}_{4}$ concentration (ppm) and CMF values (unitless) for three different flux rates (250, 500,1000 standard cubic feet per hour) at the controlled release site near Bakersfield, CA, on 28 April 2015. The max values (top panel) represent the highest concentration/CMF values in the vicinity of the release point above background values, while the total value (bottom panel) represents the accumulated sum of quantitative/CMF values over the detected plume pixels determined from thresholding the CMF result. The quantitative retrieval and CMF results have high correlation (0.992 and 0.988), which gives confidence in using the more efficient CMF method to rapidly detect and attribute methane plume point sources when compared to the more rigorous and slower retrieval approach $\left(<0.1 \mathrm{~s} \mathrm{pixel}^{-1}\right.$ for the CMF as opposed to $12 \mathrm{~s} \mathrm{pixel}^{-1}$ on average for the retrieval).

from the plume in the same scene. Similarly for the CMF result, the dMax represents the pixel with the maximum CMF value for detected plume pixels above the average background CMF value. Similarly the total values (dTotal) for the CMF and quantitative retrieval in Table 2 represent the sum of all detected plume pixels as identified by threshold- ing the CMF values; $\mathrm{dTotal}=\sum_{i=1}^{n} \mathrm{CH}_{4}(\mathrm{i})-\mathrm{BKG}$, where $n$ is the total number of detected plume pixels.

Figure 11 shows scatter plots of dMax and dTotal $\mathrm{CH}_{4}$ mole fraction (ppm) and CMF values (unitless) for the three different flux rates $(250,500,1000 \mathrm{SCFH})$, with both quantities increasing with flux rate. The error bars for the CMF were determined from the CMF variance across detected plume pixels, and for the quantitative retrieval were determined from the retrieval error analysis of various sources (e.g., air temperature, emissivity, water vapor). The quantitative retrieval and CMF results have high correlation (0.992 and 0.988) for both dMax and dTotal metrics, which gives confidence in using the more efficient CMF method to rapidly detect and attribute methane plume point sources when compared to the more rigorous and slower retrieval approach $\left(<0.1 \mathrm{~s} \mathrm{pixel}^{-1}\right.$ for the CMF as opposed to $\sim 12 \mathrm{~s} \mathrm{pixel}^{-1}$ on average for the retrieval). These results also give confidence in using the $\mathrm{CMF}$ and retrieval approaches in a synergistic manner, for example the CMF approach could be used to first rapidly detect and identify locations of methane plumes from a large aerial survey, and using this information, selected plumes can be quantified in a more rigorous manner with full uncertainty statistics using the quantitative retrieval approach.

\subsection{Multiple chemical species detection}

The following section demonstrates a few examples of the capability of HyTES to detect multiple chemical gas species. The ability to distinguish between different trace gas signatures within a single plume consisting of several contiguous pixels is a key advantage of TIR hyperspectral data. The different chemical species that will be shown include $\mathrm{NH}_{3}, \mathrm{SO}_{2}$, $\mathrm{H}_{2} \mathrm{~S}$, and $\mathrm{CH}_{4}$ and their distinctive features in the infrared domain from 7.5 to $12 \mu \mathrm{m}$ are shown in Fig. 5 .

\subsubsection{El Segundo refinery and power plant, Los Angeles}

HyTES surveyed a refinery and natural gas-fired plant in El Segundo, California, on 5 July 2014. The purpose of this flight and other flights over industrial facilities in this region was to demonstrate the capability of detecting multiple chemical trace gas species simultaneously from different processes. This capability could be used in the future to efficiently monitor both regulated and fugitive emission sources in industrial zones that are challenging to detect from the surface. Detection of fugitive emissions from airborne imagery can provide key information to identify the problem and enable mitigation, as well as improve inventories.

HyTES flew two lines over the El Segundo facility at an altitude of $1.1 \mathrm{~km}$ a.g.l. (pixel resolution $2 \mathrm{~m}$ ). The target absorption spectra for $\mathrm{SO}_{2}, \mathrm{NO}_{2}, \mathrm{NH}_{3}, \mathrm{H}_{2} \mathrm{~S}$, and $\mathrm{CH}_{4}$ (Fig. 5) were extracted from the HITRAN 2012 database and used simultaneously with the CMF method to observe any en- 


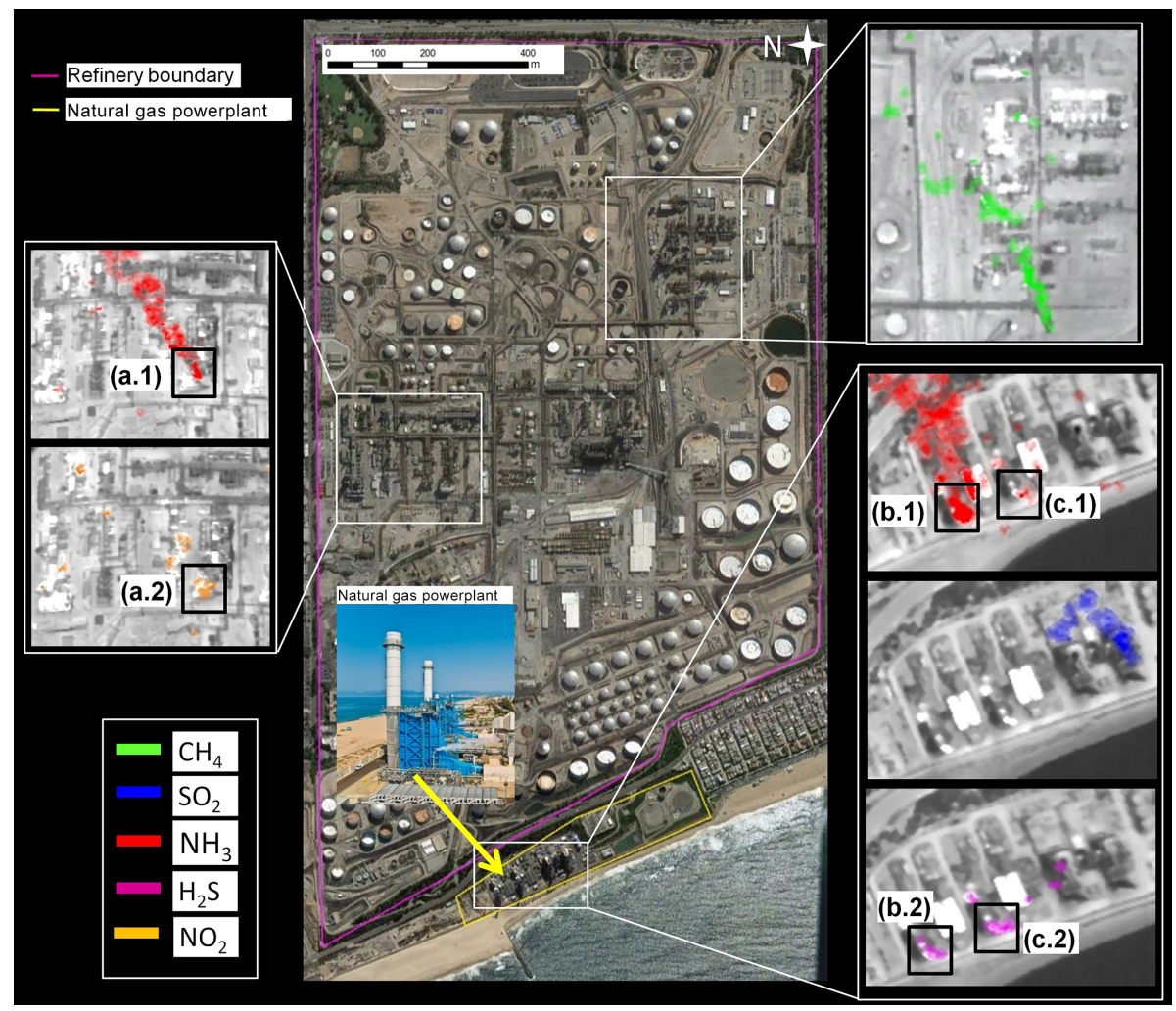

Figure 12. A HyTES multi-species gas detection example showing a Google Earth image (center) of the area covered by a HyTES flight line over a refinery (magenta outline) and a natural gas power plant (yellow outline) near El Segundo, CA. The insets show HyTES imagery of five detected trace gases $\left(\mathrm{CH}_{4}, \mathrm{NO}_{2}, \mathrm{NH}_{3}, \mathrm{H}_{2} \mathrm{~S}\right.$, and $\left.\mathrm{SO}_{2}\right)$ highlighted in different colors and overlayed on retrieved surface temperature data in grayscale. Three examples are indicated where two different gases were detected simultaneously within the same plume consisting of several contiguous pixels; $\mathrm{NH}_{3}$ and $\mathrm{NO}_{2}$ were detected over the refinery at the location a.1/a.2, while at the natural gas power plant, $\mathrm{NH}_{3}$ and $\mathrm{H}_{2} \mathrm{~S}$ were detected at location b.1/b.2, and c.1/c.2 respectively. Small plumes of $\mathrm{SO}_{2}$ (blue) can also clearly be seen being emitted from areas of the power plant (inset photograph). A distinctive $\mathrm{CH}_{4}$ plume was detected in the southeastern region of the refinery.

hancements in the vicinity of the plant. Figure 12 shows the area covered by a HyTES flight line over the El Segundo refinery and a gas-fired power plant. Insets show HyTES imagery of the five detected trace gases highlighted in different colors and overlayed on retrieved grayscale surface temperature data. Three examples are indicated where two different chemical species were detected simultaneously within the same plume consisting of several contiguous pixels: $\mathrm{NH}_{3}$ and $\mathrm{NO}_{2}$ were detected over the refinery, while $\mathrm{NH}_{3}$ and $\mathrm{H}_{2} \mathrm{~S}$ were detected in two distinct plumes over the natural gas power plant, both highlighted in Fig. 12. A distinctive $\mathrm{CH}_{4}$ plume was also detected in the southeastern region of the refinery and a $\mathrm{SO}_{2}$ plume was detected at the power plant. It is beyond the scope of this study to determine the controlling process for each of these sources; however, $\mathrm{NO}_{2}$ and $\mathrm{SO}_{2}$ emissions are often products of combustion, and $\mathrm{NH}_{3}$ and $\mathrm{H}_{2} \mathrm{~S}$ are known to be produced from post-combustion pollution control technologies used in natural gas-fired power plants. In situ mobile surveys have also shown elevated methane levels in this vicinity (Francesca Hopkins, Jet Propulsion Laboratory, personal communica- tion, 2016). Successful detection of a variety of different chemical species at such fine scale gives confidence in being able to detect similar emissions at other combustion power plants and refineries in addition to detecting $\mathrm{SO}_{2}$ from natural sources such as over volcanic regions (Realmuto et al., 1994).

\section{Discussion}

The results presented here demonstrate the strength of high spatial resolution TIR imaging spectroscopy for detecting localized sources for a variety of chemical trace gas species including $\mathrm{CH}_{4}, \mathrm{NH}_{3}, \mathrm{SO}_{2}, \mathrm{H}_{2} \mathrm{~S}$, and $\mathrm{NO} 2$. Through spectroscopic analysis of HyTES TIR imagery using a clutter matched filter (CMF) approach, we were able to detect elevated concentrations of these trace gases in spatial patterns that, given the winds, appeared to be consistent with emission plumes from point sources. In most cases we were able to infer the specific location of these sources down to spatial scales of a few meters using accurate geolocation information provided with the HyTES data. 
Atmospheric methane was detected over a wide variety of different sources including fugitive emissions from oil and gas fields, landfills, and dairies. From the 2014 and 2015 HyTES data campaigns, more than 100 individual point sources of methane were characterized in the Kern River and Elk Hills oil and gas fields in the SJV, with most emissions originating from large infrastructure such as storage and processing facilities, and distribution pipes, rather than active well heads.

CMF plume imagery are useful for rapidly identifying the location of large and persistent point source emissions, including attribution of source types. This information has been used to focus subsequent analysis with more computationally intensive, quantitative retrieval algorithms (Kuai et al., 2016). "Quicklook" CMF images can be generated on demand for any specific target gas within a few hours of the observation time, although not part of routine HyTES processing, to assist with rapid deployment of ground teams to measure in situ concentrations of the identified plumes using various instruments such as open-path in situ gas analyzers and thermal infrared cameras.

\section{Conclusion}

This study demonstrates the capability of the HyTES to detect and characterize atmospheric plumes of multiple trace gas species $\left(\mathrm{CH}_{4}, \mathrm{H}_{2} \mathrm{~S}, \mathrm{NH}_{3}, \mathrm{NO}_{2}\right.$, and $\left.\mathrm{SO}_{2}\right)$ for individual emission sources at high spatial resolution over larger areas $\left(100 \mathrm{~s}\right.$ of $\left.\mathrm{km}^{2}\right)$ under representative field conditions. HyTES produces wide-swath thermal infrared (TIR) images at high spectral (256 bands from 7.5 to $12 \mu \mathrm{m}$ ) and spatial resolution ( $\sim 2 \mathrm{~m}$ at $1 \mathrm{~km}$ altitude), and presents a major advance in airborne TIR hyperspectral remote sensing measurements. HyTES can characterize the spatial extent and identify the specific source for individual gas plumes for moderate to strong emitters. Of particular interest is the characterization of methane point sources that remain highly uncertain.

Three HyTES science campaigns during the summer of 2014 and winter/spring of 2015 targeted a variety of trace gas sources such as oil fields, gas pipelines, landfills, and dairies in the state of California. Using a hybrid clutter matched filter (CMF) technique and plume dilation algorithm, HyTES successfully detected more than 100 discrete and persistent methane sources over the oil and dairy farms in the San Joaquin Valley (SJV), California. Spatial patterns of methane plumes detected by HyTES were consistent with coincident in situ methane profile and wind measurements at the surface and from other aircraft. In addition to the HyTES plume detection/attribution capability, a HyTES methane concentration retrieval algorithm was developed and adapted from the algorithm used for retrieving trace gases from the TES instrument on board the Aura Satellite.

A controlled release experiment of methane gas in the Bakersfield region demonstrated that HyTES could detect methane fluxes as small as $250 \mathrm{SCFH}\left(5 \mathrm{~kg} \mathrm{CH}_{4} \mathrm{~h}^{-1}\right)$ at
$500 \mathrm{~m}$ flight altitude with $\sim 2 \mathrm{~m} \mathrm{~s}^{-1}$ winds. The controlled release results also showed high correlation between the CMF and concentration retrieval results, which gives confidence in using these two approaches in a synergistic manner. For example, the CMF approach could be used to first rapidly detect and identify locations of methane plumes from broad aerial surveys, and then guide focused application of the full methane algorithm to generate quantitative estimates in a more rigorous manner with a full set of uncertainty statistics to help address key science questions.

The quantitative retrieval capability combined with highresolution wind data will be used in the future to support emission flux estimation of methane point sources. The high spatial resolution imaging capability of HyTES for methane and other trace gas plumes will help fill an important niche in tiered observing strategies by complementing the larger coverage but coarser spatial resolution offered by satellite methane observations and high measurement accuracy of mobile surface in situ observations. Collectively, these measurement systems offer new tools for improving scientific understanding and decision-making associated with methane emission sources.

\section{Data availability}

HyTES L2 and L3 data are available for ordering free of charge at http://hytes.jpl.nasa.gov/order (Jet Propulsion Laboratory, 2016).

Acknowledgements. The research described in this paper was carried out at the Jet Propulsion Laboratory, California Institute of Technology, under contract with the National Aeronautics and Space Administration. Many thanks to Francois Rongere from Pacific Gas and Electric's R\&D and Innovation division for their support for the controlled release test.

Edited by: H. Worden

\section{References}

Aires, F., Chedin, A., Scott, N. A., and Rossow, W. B.: A regularized neural net approach for retrieval of atmospheric and surface temperatures with the IASI instrument, J. Appl. Meteorol., 41, 144-159, 2002.

Beer, R.: TES on the Aura mission: Scientific objectives, measurements, and analysis overview, IEE T. Geosci. Remote, 44, 11021105, 2006.

Berk, A., Anderson, G. P., Acharya, P. K., Bernstein, L. S., Muratov, L., Lee, J., Fox, M., Adler-Golden, S. M., Chetwynd, J. H., Hoke, M. L., Lockwood, R. B., Gardner, J. A., Cooley, T. W., Borel, C. C., and Lewis, P. E.: MODTRAN ${ }^{\mathrm{TM}}$ 5, A Reformulated Atmospheric Band Model with Auxiliary Species and Practical Multiple Scattering Options: Update, in Proc SPIE, Algorithms and Technologies for Multispectral, Hyperspectral, and Ultraspectral Imagery XI, Bellingham, WA, USA, 662-667, 2005. 
Borbas, E., Knuteson, R., Seemann, S. W., Weisz, E., Moy, L., and Huang, H.: A high spectral resolution global land surface infrared emissivity database, Joint 2007 EUMETSAT Meteorological Satellite \& 15th AMS Satellite Meteorology and Oceanography Conference, 24-28 September 2007, Amsterdam, the Netherlands, available at: http://www.ssec.wisc.edu/meetings/ jointsatmet2007/pdf/borbas_emissivity_database.pdf (last access: 20 May 2016), 2007.

Broadwater, J. B., Spisz, T. S., and Carr, A. K.: Detection of gas plumes in cluttered environments using long-wave infrared hyperspectral sensors, Proc. of SPIE 6954, 69540R-169540R$169512,2008$.

Damm, E., Helmke, E., Thoms, S., Schauer, U., Nöthig, E., Bakker, K., and Kiene, R. P.: Methane production in aerobic oligotrophic surface water in the central Arctic Ocean, Biogeosciences, 7, 1099-1108, doi:10.5194/bg-7-1099-2010, 2010.

Dlugokencky, E. J., Bruhwiler, L., White, J. W. C., Emmons, L. K., Novelli, P. C., Montzka, S. A., Masarie, K. A., Lang, P. M., Crotwell, A. M., Miller, J. B., and Gatti, L. V.: Observational constraints on recent increases in the atmospheric $\mathrm{CH}_{4}$ burden, Geophys. Res. Lett., 36, L18803, doi:10.1029/2009GL039780, 2009.

Doneus, M., Verhoeven, G., Atzberger, C., Wess, M., and Rus, M.: New ways to extract archaeological information from hyperspectral pixels, J. Archaeol. Sci., 52, 84-96, 2014.

EPA: Inventory of U.S. greenhouse gas emissions and sinks: 19902009, United States Environmental Protection Agency (EPA), Washington, D.C., USA, 2011.

Ferrec, Y., Rousset-Rouviere, L., Coudrain, C., Primot, J., Thetas, S., and Kattnig, A.: SYSIPHE: focus on SIELETERS, the medium and longwave infrared spectral imaging instrument, Proc. SPIE 9104, Baltimore, Maryland, USA, 2014.

Funk, C. C., Theiler, J., Roberts, D. A., and Borel, C. C.: Clustering to improve matched filter detection of weak gas plumes in hyperspectral thermal imagery, IEEE T. Geosci. Remote, 39, 1410-1420, 2001.

Green, R. O., Eastwood, M. L., Sarture, C. M., Chrien, T. G., Aronsson, M., Chippendale, B. J., Faust, J. A., Pavri, B. E., Chovit, C. J., Solis, M. S., Olah, M. R., and Williams, O.: Imaging spectroscopy and the Airborne Visible Infrared Imaging Spectrometer (AVIRIS), Remote Sens. Environ., 65, 227-248, 1998.

Gunapala, S. D., Bandara, S. V., Liu, J. K., Hill, C. J., Rafol, S. B., Mumolo, J. M., Trinh, J. T., Tidrow, M. Z., and LeVan, P. D.: Multicolor megapixel QWIP focal plane arrays for remote sensing instruments, Proc. SPIE 5983, P. Soc. Photo-Opt. Ins., Bruges, Belgium, 63080P, 2006.

Hackwell, J. A., Warren, D. W., Bongiovi, R. P., Hansel, S. J., Hayhurst, T. L., Mabry, D. J., Sivjee, M., and Skinner, J.: LWIR/MWIR Imaging Hyperspectral Sensor for Airborne and Ground-Based Remote Sensing, Proc. SPIE 2819, Imaging Spectrometry II, Denver, CO, 102-107, 1996.

Hall, J. L., Hackwell, J., Tratt, D. M., Warren, D. W., and Young, S. J.: Space-based mineral and gas identification using a highperformance thermal infrared imaging spectrometer, Proc. SPIE 7082, P. Soc. Photo-Opt. Ins., San Diego, CA, USA, 70820M, 2008.

Hall, J. L., Boucher, R. H., Buckland, K. N., Gutierrez, D. J., Hackwell, J. A., Johnson, B. R., Keim, E. R., Moreno, N. M., Ramsey, M. S., Sivjee, M. G., Tratt, D. M., Warren, D. W., and Young, S.
J.: MAGI: A New High-Performance Airborne Thermal-Infrared Imaging Spectrometer for Earth Science Applications, IEEE T. Geosci. Remote, 53, 5447-5457, 2015.

Ham, J. M. and DeSutter, T. M.: Toward site-specific design standards for animal-waste lagoons: Protecting ground water quality, J. Environ. Qual., 29, 1721-1732, 2000.

Hook, S., Johnson, W., and Abrams, M.: NASA's Hyperspectral Thermal Emission Spectrometer (HyTES), in: Thermal Infrared Remote Sensing - Sensors, Methods, Applications, edited by: Kuenzer, C. and Dech, S., Springer, Dordrecht, the Netherlands, 2013.

Hook, S. J., Myers, J. E. J., Thome, K. J., Fitzgerald, M., and Kahle, A. B.: The MODIS/ASTER airborne simulator (MASTER) - a new instrument for earth science studies, Remote Sens. Environ., 76, 93-102, 2001.

Hook, S. J., Hulley, G. C., Johnson, W. R., Eng, B., Mihaly, J., Chazanoff, S., Vance, N., Staniszewski, Z., Rivera, G., Holmes, K. T., and Guillevic, P.: The Hyperspectral Thermal Emission Spectrometer (HyTES) - A New Hyperspectral Thermal Infrared Airborne Imager for Earth Science, Remote Sens. Environ, in press, 2016.

Hulley, G. C., Guillevic, P., Vance, N., Rivera, G., Hook, S. J., Radocinski, R. G., Grigsby, S., and Roberts, D. A.: HyspIRIMASTER-HyTES Land Surface Temperature and Emissivity Products and Enhancements, HyspIRI Science and Applications Workshop, 14-16 October 2014, Pasadena, CA, available at: http://hyspiri.jpl.nasa.gov/documents/2014-workshop (last access: 25 May 2016), 2014.

Hulley, G. C., Hook, S. J., Abbott, E., Malakar, N., Islam, T., and Abrams, M.: The ASTER Global Emissivity Database (ASTER GED): Mapping Earth's emissivity at 100 meter spatial scale, Geophys. Res. Lett., 42, doi:10.1002/2015GL065564, 2015.

Jet Propulsion Laboratory: Hyperspectral Thermal Emission Spectrometer (HyTES), available at: http://hytes.jpl.nasa.gov, last access: 25 May 2016.

Johnson, W. R., Hook, S. J., Mouroulis, P., Wilson, D. W., Gunapala, S. D., Hill, C. J., Mumolo, J. M., Realmuto, V., and Eng, B. T.: Towards HyTES: an airborne thermal imaging spectroscopy instrument, Proc. SPIE 7457, P. Soc. Photo-Opt. Ins., San Diego, CA, USA, 745706, 2009.

Johnson, W. R., Hook, S. J., Foote, M., Eng, B. T., and Jau, B.: Infrared instrument support for HyspIRI-TIR, Proc. SPIE 8511, P. Soc. Photo-Opt. Ins., San Diego, CA, USA, 851102, 2012.

Kahle, A. B. and Goetz, A. F. H.: Mineralogic Information from a New Airborne Thermal Infrared Multispectral Scanner, Science, 222, 24-27, 1983.

Kirschke, S., Bousquet, P., Ciais, P., Saunois, M., Canadell, J. G., Dlugokencky, E. J., Bergamaschi, P., Bergmann, D., Blake, D. R., Bruhwiler, L., Cameron-Smith, P., Castaldi, S., Chevallier, F., Feng, L., Fraser, A., Heimann, M., Hodson, E. L., Houweling, S., Josse, B., Fraser, P. J., Krummel, P. B., Lamarque, J. F., Langenfelds, R. L., Le Quere, C., Naik, V., O’Doherty, S., Palmer, P. I., Pison, I., Plummer, D., Poulter, B., Prinn, R. G., Rigby, M., Ringeval, B., Santini, M., Schmidt, M., Shindell, D. T., Simpson, I. J., Spahni, R., Steele, L. P., Strode, S. A., Sudo, K., Szopa, S., van der Werf, G. R., Voulgarakis, A., van Weele, M., Weiss, R. F., Williams, J. E., and Zeng, G.: Three decades of global methane sources and sinks, Nat. Geosci., 6, 813-823, 2013. 
Kort, E. A., Wofsy, S. C., Daube, B. C., Diao, M., Elkins, J. W., Gao, R. S., Hintsa, E. J., Hurst, D. F., Jimenez, R., Moore, F. L., Spackman, J. R., and Zondlo, M. A.: Atmospheric observations of Arctic Ocean methane emissions up to 82 degrees north, Nat. Geosci., 5, 318-321, 2012.

Kuai, L., Worden, J. R., Li, K., Hulley, G. C., Hopkins, F. M., Miller, C. E., Hook, S. J., Duren, R. M., and Aubrey, A. D.: Characterization of anthropogenic methane plumes with the Hyperspectral Thermal Emission Spectrometer (HyTES): a retrieval method and error analysis, Atmos. Meas. Tech. Discuss., doi:10.5194/amt-2015-402, in review, 2016.

Larsen, K., Delgado, M., and Marsters, P.: Untapped Potential: Reducing Global Methane Emissions from Oil and Natural Gas Systems, Rhodium Group, LLC, New York, NY, USA, 2015.

Leifer, I.: Flying the Methane Drift - Airborne and Surface Measurements to Validate Methane Remote Sensing Retrievals and Atmospheric Correction for the HyspIRI and COMEX Campaigns, HyspIRI Workshop, 17-18 March 2014, NASA HQ, Washington D.C., USA, 2014.

Liang, Z. S., Westerman, P. W., and Arogo, J.: Modeling ammonia emission from swine anaerobic lagoons, T. ASAE, 45, 787-798, 2002.

Miller, S. M., Worthy, D. E. J., Michalak, A. M., Wofsy, S. C., Kort, E. A., Havice, T. C., Andrews, A. E., Dlugokencky, E. J., Kaplan, J. O., Levi, P. J., Tian, H. Q., and Zhang, B. W.: Observational constraints on the distribution, seasonality, and environmental predictors of North American boreal methane emissions, Global Biogeochem. Cy., 28, 146-160, 2014.

Realmuto, V. J., Abrams, M. J., Buongiorno, M. F., and Pieri, D. C.: The Use of Multispectral Thermal Infrared Image Data to Estimate the Sulfur-Dioxide Flux from Volcanos - a Case-Study from Mount Etna, Sicily, July 29, 1986, J. Geophys. Res.-Sol. Ea., 99, 481-488, 1994.

Rigby, M., Prinn, R. G., Fraser, P. J., Simmonds, P. G., Langenfelds, R. L., Huang, J., Cunnold, D. M., Steele, L. P., Krummel, P. B., Weiss, R. F., O'Doherty, S., Salameh, P. K., Wang, H. J., Harth, C. M., Muhle, J., and Porter, L. W.: Renewed growth of atmospheric methane, Geophys. Res. Lett., 35, L22805, doi:10.1029/2008GL036037, 2008.

Ro, K. S., Johnson, M. H., Stone, K. C., Hunt, P. G., Flesch, T., and Todd, R. W.: Measuring gas emissions from animal waste lagoons with an inverse-dispersion technique, Atmos. Environ., 66, 101-106, 2013.

Roberts, D. A., Bradley, E. S., Cheung, R., Leifer, I., Dennison, P. E., and Margolis, J. S.: Mapping methane emissions from a marine geological seep source using imaging spectrometry, Remote Sens. Environ., 114, 592-606, 2010.
Theiler, J. and Foy, B. R.: Effect of signal contamination in matched-filter detection of the signal on a cluttered background, IEEE Geosci. Remote S., 3, 98-102, 2006.

Thomas, G. and Zachariah, E. J.: Ground level volume mixing ratio of methane in a tropical coastal city, Environ. Monit. Assess. 184, 1857-1863, 2012.

Thompson, D. R., Leifer, I., Bovensmann, H., Eastwood, M., Fladeland, M., Frankenberg, C., Gerilowski, K., Green, R. O., Kratwurst, S., Krings, T., Luna, B., and Thorpe, A. K.: Real-time remote detection and measurement for airborne imaging spectroscopy: a case study with methane, Atmos. Meas. Tech., 8, 4383-4397, doi:10.5194/amt-8-4383-2015, 2015.

Thorpe, A. K., Roberts, D. A., Bradley, E. S., Funk, C. C., Dennison, P. E., and Leifer, I.: High resolution mapping of methane emissions from marine and terrestrial sources using a ClusterTuned Matched Filter technique and imaging spectrometry, Remote Sens. Environ., 134, 305-318, 2013.

Thorpe, A. K., Frankenberg, C., and Roberts, D. A.: Retrieval techniques for airborne imaging of methane concentrations using high spatial and moderate spectral resolution: application to AVIRIS, Atmos. Meas. Tech., 7, 491-506, doi:10.5194/amt-7491-2014, 2014.

Tobin, D. C., Revercomb, H. E., Knuteson, R. O., Lesht, B. M., Strow, L. L., Hannon, S. E., Feltz, W. F., Moy, L. A., Fetzer, E. J., and Cress, T. S.: Atmospheric Radiation Measurement site atmospheric state best estimates for Atmospheric Infrared Sounder temperature and water vapor retrieval validation, J. Geophys. Res.-Atmos., 111, D09S14, doi:10.1029/2005JD006103, 2006.

Tratt, D. M., Buckland, K. N., Hall, J. L., Johnson, P. D., Keim, E. R., Leifer, I., Westberg, K., and Young, S. J.: Airborne visualization and quantification of discrete methane sources in the environment, Remote Sens. Environ., 154, 74-88, 2014.

Warren, D. W., Boucher, R. H., Gutierrez, D. J., Keim, E. R., and Sivjee, M. G.: MAKO: A high-performance, airborne imaing spectrometer for the long-wave infrared, Proc. SPIE 7812, P. Soc. Photo-Opt. Ins., San Diego, CA, USA, 78120N, 2010.

Young, S. J., Johnson, B. R., and Hackwell, J. A.: An in-scene method for atmospheric compensation of thermal hyperspectral data, J. Geophys. Res.-Atmos., 107, 4774 doi:10.1029/2001JD001266, 2002. 